\title{
A theoretical investigation into thiophenic derivative cracking mechanism over acidic and cation-exchanged beta zeolites
}

\author{
Xinfeng $\mathrm{Mao}^{\dagger}$, Yingxin Sun ${ }^{* \dagger}$, and Supeng Pei ${ }^{* \dagger}$ \\ ${ }^{\dagger}$ School of Chemical and Environmental Engineering, Shanghai Institute of \\ Technology
}

*Corresponding authors: Yingxin Sun and Supeng Pei

Tel: +86-21-6087-7214

E-mail address: sunyingxin0312@sit.edu.cn and peisupeng@126.com 


\begin{abstract}
A Two-layer ONIOM study has been carried out to investigate the unimolecular and bimolecular cracking mechanisms of thiophene catalyzed by acidic and metal cation-exchanged $\left(\mathrm{Li}^{+}, \mathrm{Na}^{+}, \mathrm{K}^{+}, \mathrm{Cu}^{+}\right.$, and $\left.\mathrm{Ag}^{+}\right)$beta zeolites. The unimolecular cracking reactions of 3,4-dimethylthiophene (3,4-DMT) and benzothiophene (BT) catalyzed by acidic beta zeolite are also calculated. It was found that the rate-determining steps in these two mechanisms are both $\mathrm{C}-\mathrm{S}$ bond cracking. Furthermore, the activation energy of $\mathrm{C}-\mathrm{S}$ bond cracking in bimolecular mechanism is lower than that in unimolecular mechanism, indicating that the bimolecular cracking process is more favorable. In addition, although the activation energies of $\mathrm{C}-\mathrm{S}$ bond cleavage of 3,4-DMT and BT over H-beta zeolite are relatively lower than thiophene, the practical process would be difficult to occur due to still high energy barriers. A close analysis of activation energies over cation-exchanged zeolites suggests that the metal cations do not reduce and contrarily increase their difficulty of thiophene cracking reactions.
\end{abstract}

Keywords thiophene; C-S bond cracking; Beta zeolite; cation-exchanged zeolites; bimolecular mechanism 


\section{Introduction}

Sulfur species in fuel oils are directly responsible for $\mathrm{SO}_{\mathrm{x}}$ emissions, which not only causes acid rain but also poisons the noble metal catalysts in the exhaust gas converter for reducing $\mathrm{CO}, \mathrm{NO}_{\mathrm{x}}$, and particulate matter [1-3]. Deep desulfurization of fuel oils has became an urgent subject worldwide owing to the increasing stringent environmental regulations [4,5]. The main industrial process to produce clean fuels is hydrodesulfurization (HDS), usually at high temperatures and $\mathrm{H}_{2}$ pressures, and traditional HDS catalysts generally consist of $\gamma$-alumina supported molybdenum sulfide promoted by $\mathrm{Ni}$ or $\mathrm{Co}$ [6-8]. Conventional HDS is effective in the elimination of reactive sulfides and mercaptans, but difficult to remove refractory molecules such as thiophene, benzothiophene and their derivatives. The production of ultra-low sulfur gasoline by HDS requires considerable hydrogen consumption and inevitably lead to decrease of octane number since olefin saturation $[9,10]$.

Interestingly, many studies have suggested that zeolites alone can catalyze thiophene desulfurization [11-16]. Angelis et al. [17] found the $\mathrm{C}-\mathrm{S}$ bond cracking of thiophene and the formation of $-\mathrm{SH}$ groups over $\mathrm{H}-\mathrm{Y}$ zeolites by an infrared approach. Garcia and Lercher [11,12] demonstrated that it is too stable to induce further reactions after the adsorption of thiophene on NaZSM-5, KZSM-5, and HZSM-5 at a coverage of less than 1 molecule per acid site. Only at higher thiophene coverage on HZSM-5, the catalytic reaction could proceed. The catalytic process undergoes intermolecular hydrogen transfer, the thiophene ring-opening, and forms thiol-like complexes with $-\mathrm{CH}_{2}$ groups close to a sulfur atom or to a double bond. However, such activity could not be found on NaZSM-5 and KZSM-5. Shan et al. [18] suggested that there are two essential steps for thiophene and alkyl-thiophene desulfurization over USY zeolite. One is the cracking of $\mathrm{C}-\mathrm{S}$ bond and the other one is hydrogen transfer. The former step is favorable at high temperatures, while the latter is dominant at low temperatures, and the optimal temperature is about $400{ }^{\circ} \mathrm{C}$. Gong et al. [19] studied the deep desulfurization capacities of $\mathrm{Cu}(\mathrm{I})$ and $\mathrm{Ag}(\mathrm{I})$ exchanged beta zeolites. They found that $\mathrm{Cu}(\mathrm{I})$ - and $\mathrm{Ag}(\mathrm{I})$-beta zeolites could reduce sulfur compounds of model gasoline from about $200 \mathrm{ppm}$ to below $1 \mathrm{ppm}$ in the ambient conditions.

Although a large progress has been achieved in the experimental research of thiophene desulfurization over the past few decades, atomic-level knowledge of cracking mechanism of thiophene derivatives is still scarce due to the complicated HDS reaction network catalyzed by zeolites. Elucidation of microscopic reaction 
pathways is helpful for experimental work to improve desulfurization selectivities of zeolites more efficiently. However, it is difficult to explore experimentally these atomic-level information of reaction mechanisms. Theoretical methods might be the only and best choice.

Bare cluster model and periodic density functional theory (DFT) are two popular quantum chemistry methods. Saintigny et al. [20] investigated the desulfurization reaction of thiophene on $\mathrm{H}_{3} \mathrm{SiOHAl}(\mathrm{OH})_{2} \mathrm{OSiH}_{3}$ (3T) zeolitic cluster using a DFT-based method. They compared two different mechanisms: one occurring with the participation of hydrogen and another without hydrogen. Interestingly, they found that the activation barriers of thiophene ring-opening for two mechanisms are both about $222 \mathrm{~kJ} / \mathrm{mol}$. Rozanska et al. [21] applied a tetrahedral 4T model to investigate the mechanisms of thiophene cracking reaction. They reported that the Brønsted acid site just indirectly participates in the controlling reaction. The use of assisting molecules $\left(\mathrm{H}_{2} \mathrm{O}\right.$ and $\left.\mathrm{H}_{2} \mathrm{~S}\right)$ effectively reduce the cracking activation energy. They also predicted that this reaction even can be catalyzed by alkoxy species or Li-exchanged zeolite. Furthermore, Rozanska et al. [22] performed a periodic DFT study to investigate the cracking process of thiophene, dihydrothiophene, and dibenzothiophene catalyzed by proton- or lithium-exchanged MOR zeolite. Their calculations showed that the activation energies of thiophenic derivative cracking are in the range $270-320 \mathrm{~kJ} / \mathrm{mol}$ and concluded that the transition state complexes could not be stabilized by zeolite framework. Li et al. [23] also reported a mechanism of thiophene cracking on acidic zeolite by DFT calculations. The mechanism involves two major steps: the first step is protonation of thiophene to form 2-(2,5-dihydrothiophen-2-yl) thiophene and is rate-determining step. The second step is $\mathrm{C}-\mathrm{S}$ bond dissociation of the 2,5-dihydrothiophene with a lower barrier. In addition, Lee et al. [24] investigated the adsorption desulfurization properties of acidic and cation-exchanged zeolites for the organosulfur compounds (tetrahydrothiophene, dimethylsulfide, $\mathrm{H}_{2} \mathrm{~S}$, and so on) using DFT method. They found that $\mathrm{Ag}^{+}$cation significantly enhance the adsorption energies of the sulfur compounds compared with the $\mathrm{H}^{+}$and $\mathrm{Na}^{+}$because of strong $\mathrm{Ag}^{+}-\mathrm{S}$ bond interactions.

The simple cluster model can accurately describe local catalytic reactions near active acidic sites, but this method makes it difficult to understand the influence of zeolite environment. The periodic DFT approach is too expensive to compute very large zeolites framework. Recently, many studies have proposed a quantum mechanical/molecular mechanical (QM/MM) method [25-27] and the more general 
ONIOM (Our-own-N-layered Integrated molecular Orbital + molecular Mechanics) scheme [28-30]. The QM/MM method as well as the ONIOM scheme combines the advantages of the high accuracy of quantum chemistry calculations and the high efficiency of using a molecular mechanics force field to represent long-range interactions. We have investigated successfully several reaction mechanisms catalyzed by zeolites using QM/MM in previous studies.

In this work, we carried out a theoretical study of the HDS reaction mechanism of thiophene cracking catalyzed by acidic $\mathrm{H}$-beta and cation-exchanged $\mathrm{M}$-beta $(\mathrm{M}=$ $\mathrm{Li}^{+}, \mathrm{Na}^{+}, \mathrm{K}^{+}, \mathrm{Cu}^{+}$, and $\mathrm{Ag}^{+}$) zeolites, based on a two-layer ONIOM approach. Our objective is to solve the following several questions: (1) How do the zeolite framework affect the reaction pathway of thiophene cracking? (2) Do the participation of metal cations into zeolite improve the HDS process? (3) What is the difference of activation energy of $\mathrm{C}-\mathrm{S}$ bond breaking step for the different thiophene derivatives such as methylthiophene and benzothiophene? The current study will be helpful to design more efficient catalysts with high selectivity for HDS of thiophene.

\section{Computational Methods}

The Brønsted acid center and the zeolite framework were represented by an extended 188T cluster of the H-beta zeolite in our work. The dimensions of this model were taken from crystallographic data of $\mathrm{H}$-beta cell with space group $P 4_{1} 22(\mathrm{a}=\mathrm{b}=$ $12.661 \AA, c=26.406 \AA, \alpha=\beta=\gamma=90.0^{\circ}$ ) [31]. Fig. 1 shows the $188 \mathrm{~T}$ model in which the main gateway to the intersection area of two perpendicular channels A and $\mathrm{B}$ is represented by a 12-membered-ring (12MR). An Si atom at the T5 site in the model is replaced with an $\mathrm{Al}$ atom. According to our previous study [32], among the four bridging oxygen atoms $(\mathrm{Oa}, \mathrm{Ob}, \mathrm{Oc}, \mathrm{Od})$ that directly bond to the $\mathrm{Al}$ atom, $\mathrm{Oa}$ and $\mathrm{Ob}$ were chosen as the most likely proton positions, because they have lower energies than the Oc and Od positions. The acidic proton $\mathrm{H}$ is replaced by metal cations such as $\mathrm{M}=\mathrm{Li}^{+}, \mathrm{Na}^{+}, \mathrm{K}^{+}, \mathrm{Cu}^{+}$, and $\mathrm{Ag}^{+}$to produce the cation-exchanged M-beta zeolite. The dangling $\mathrm{Si}$ atoms from cutting the outer $\mathrm{Si}-\mathrm{O}$ bonds were terminated with $\mathrm{H}$ atoms, with the $\mathrm{Si}-\mathrm{H}$ bond distances fixed at $1.470 \AA$. The present computational model with a single acidic site is simple but very important to explore the fundamental characteristics of reaction mechanisms and has been used successfully and widely in previous theoretical works [23,33,34].

A two-layer ONIOM scheme was employed to all calculations in this work. In the scheme, the total energy of the whole system is attained from the following 
equation [35]:

$$
E_{\mathrm{ONOM} 2}=E_{\mathrm{MM}}^{\mathrm{All}}-E_{\mathrm{MM}}^{\mathrm{Inner}}+E_{\mathrm{QM}}^{\mathrm{Inner}}
$$

where the "all" region consists of an "inner" region and a large "outer" region. The outer region is the extended zeolite framework and is calculated in the molecular mechanics (MM) method. The inner region, which covers the active Brønsted acidic site and reactant, is computed by both quantum mechanics (QM) and MM calculations. The van der Waals (VDW) and electrostatic interaction energies are treated using the MM terms.

The errors associated with the ONIOM extrapolation method can be checked by an $S$ value test. The MM contribution to the ONIOM energy must be continuous because the ONIOM energy surface is continuous. The MM contribution is described as the $S$ value [30,36,37], i.e.,

$$
S^{\mathrm{MM}}=E_{\mathrm{MM}}^{\mathrm{All}}-E_{\mathrm{MM}}^{\mathrm{Inner}}
$$

The $S$ value does not depend on the definition of the connectivity for each intermediate and transition state (TS) structure involved in reaction pathways. We calculated several typical transition states of the desulfurization process on H-beta zeolite and found that all the $S$ values accurately equal zero, despite different choices of connectivity. The corresponding results are given in Supporting Information (SI).

In the ONIOM calculations, the inner and outer regions was optimized by using the M06-2X hybrid meta-GGA functional [38-41] and the universal force field (UFF) [42], respectively. The M06-2X functional was developed to describe medium-range van der Waals interactions more accurately than other functionals, such as the well-known B3LYP one [43]. In order to save computational time, the inner QM region was further split into two subregions that were computed using mixed basis sets. The active subregion including an $8 \mathrm{~T}$ cluster of the active site of zeolite and reacting molecules was treated using the $6-31 \mathrm{G}(\mathrm{d}, \mathrm{p})$ basis set; the other $8 \mathrm{~T}$ cluster of the inner region was treated using the 3-21G basis set. For the $\mathrm{Cu}$ and $\mathrm{Ag}$ atoms, Stuttgart RSC 1997 basis sets employing relativistic core potential were used [44]. This combination rule was called M06-2X(8T(6-31G(d,p)) : 8T(3-21G)) and the complete zeolite system was called ONIOM(16T:188T). In comparison with previous work [45], the 16T QM cluster is considered large enough to efficiently study the present reaction mechanisms. In geometry optimizations, only the $5 \mathrm{~T}$ region $\left[(\equiv \mathrm{SiO})_{3} \mathrm{Al}(\mathrm{OX}) \mathrm{Si} \equiv\right][\mathrm{X}=\mathrm{H}, \mathrm{Li}, \mathrm{Na}, \mathrm{K}, \mathrm{Cu}$, and $\mathrm{Ag}]$ and the reacting molecules were permitted to relax, whereas the rest of the $188 \mathrm{~T}$ model was fixed along the 
crystallographic coordinates. Frequency calculations were carried out to verify whether each stationary was an intermediate (no negative frequency) or a transition state (exactly only one negative frequency). Instrinsic reaction coordinate (IRC) calculations were also performed for the TSs both forward and reverse directions to determine two relevant minima [46]. To gain more reliable results, single-point energy calculations were further performed at the M06-2X(8T(6-311+G(2df,2p)) : 8T(6-31G(d,p))) and MP2(8T(6-311+G(d,p)) : 8T(6-31G(d,p))) levels, based on the above-mentioned optimized structures for the QM atoms. The latter scheme was called MP2//M06-2X and the corresponding ONIOM(MP2//M06-2X:UFF) energy values are used and discussed in this paper.

It is well-known that the adsorption energies obtained as the difference between the total energy of the complex $(\mathrm{AB})$ and the sum of the energies of the separated molecules (A or B) are always an overestimation because of the basis set superposition error (BSSE). In this work, all interaction energies were corrected using the BSSEs by means of the counterpoise (CP) scheme of Boys and Bernardi [47]. The $\mathrm{CP}$ scheme gives an estimation of the BSSE calculated as the following equation:

$$
\mathrm{BSSE}=E(\mathrm{~A})_{\mathrm{A}}-E(\mathrm{~A})_{\mathrm{AB}}+E(\mathrm{~B})_{\mathrm{B}}-E(\mathrm{~B})_{\mathrm{AB}}
$$

where $E(\mathrm{~A})_{\mathrm{A}}$ and $E(\mathrm{~B})_{\mathrm{B}}$ are the total energies of $\mathrm{A}$ and $\mathrm{B}$ molecules respectively, at their equilibrium structures. $E(\mathrm{~A})_{\mathrm{AB}}$ is the total energy of fragment $\mathrm{A}$ at its equilibrium structure in the complex $\mathrm{AB}$ and calculated with a basis set including all basis functions of fragments $\mathrm{A}$ and $\mathrm{B}$ without electrons and nuclei of fragment $\mathrm{B}$.

Because the zeolitic atom charge parameters are not optimized in the UFF, we calculated the electrostatic potential (ESP) energy of a 102T pure silica zeolite model by the M06-2X/6-31G(d,p) single-point calculations and obtained charge values for the MM region by fitting the ESP energy. The detailed method for obtaining the charge values for the QM and MM atoms has been given in our previous work [32]. A mechanical embedding scheme was used to calculate electrostatic interactions between the QM and MM regions. Gaussian 09 program package is used throughout all calculations [48]. It should be noted that the present theoretical method employed a multitude of assumptions, such as choice of mixed basis sets, choice of the zeolite cluster division, optimization scheme, and choice of QM and MM model sizes. All these choices have been adopted in published literature and thus are reasonable to save computational time [49-51].

\section{Results and Discussion}




\subsection{Unimolecular thiophene cracking over H-beta zeolite}

As shown in Scheme 1A, the cracking reaction starts with the one thiophene molecule captured by the acid site of zeolite. Two different types of adsorption modes, $\eta^{1}(\mathrm{~S})$ and $\eta^{2}(\mathrm{CC})$, are obtained, with the BSSE corrected adsorption energies of -64.73 and $-55.37 \mathrm{~kJ} / \mathrm{mol}$, respectively. The $\eta^{1}(\mathrm{~S})$ adsorption mode is more stable than the $\eta^{2}(\mathrm{CC})$ mode. This result is consistent with the previous experimental observations in the acidic zeolite [12]. The optimized structures of adsorbed thiophene, complex-TH-1, are shown in Fig. 2. In the $\eta^{1}(\mathrm{~S})$ adsorption mode, the $\mathrm{Oa}-\mathrm{H}$ distance is lengthened by $0.01 \AA$ compared with that in the pure H-beta. A hydrogen-bond is formed between the thiophene and acidic proton of zeolite with a $\mathrm{S} \cdots \mathrm{H}$ bond distance of $2.37 \AA$. In the $\eta^{2}(\mathrm{CC})$ adsorption mode, the thiophene interacts with acidic proton with two $\mathrm{H}-\mathrm{C}_{\alpha}$ and $\mathrm{H}-\mathrm{C}_{\beta}$ distances of 2.22 and $2.24 \AA$, respectively.

After the initial adsorption of thiophene, thiophenic sulfur atom will go through a protonation step which leads to thiophenic $\mathrm{C}-\mathrm{S}$ bond cracking and ring-opening with the activation energy of $426.89 \mathrm{~kJ} / \mathrm{mol}$ for TS-TH-1. Obviously, the activation energy is so high that the $\mathrm{C}-\mathrm{S}$ bond cracking process is experimentally difficult to occur. The calculated ONIOM energy and energy components in terms of QM and MM contributions of TS-TH-1 are given in Table 1. Clearly, the MM contribution is positive, which suggests that the zeolite framework appears not to stabilize the transition state structure. This unexpected result is similar to that on H-MOR zeolite obtained by Rozanska et al. They performed a periodic DFT study and found that the activation energy for C-S cracking of thiophene catalyzed by H-MOR is $318 \mathrm{~kJ} / \mathrm{mol}$, indicating the difficulty of occurrence of this cracking process [22]. Furthermore, they also pointed out that the zeolite framework does not have a stabilizing effect on the transition state structures of the thiophene cracking. The geometrical parameters of the optimized transition state TS-TH-1 is shown in Fig. 3a. It can be seen that in TS-TH-1, the acidic proton $\mathrm{H}$ is almost bonded to the sulfur atom; the $\mathrm{C}-\mathrm{S}$ bond of thiophene is breaking and ring is opening, and simultaneously the new $\mathrm{C}-\mathrm{O}$ bond is forming. The involved $\mathrm{OH} \cdots \mathrm{S}, \mathrm{C}-\mathrm{S}$, and $\mathrm{C}-\mathrm{O}$ bond distances are 1.35, 2.27, and 1.63 $\AA$, respectively. Thiophene cracking leads to the formation of an alkoxy species, INT-TH-1, with the C-O distance of $1.44 \AA$ (See Fig. 3b).

\subsection{Unimolecular thiophenic derivatives cracking over H-beta zeolite}

We calculated the cracking reactions of 3,4-dimethylthiophene (3,4-DMT) and benzothiophene (BT) over H-beta zeolite in order to understand the influence of 
electron-donating group on thiophene HDS process; the reaction pathways are shown in Schemes 1B and 1C, respectively. Similar to unimolecular thiophene, there are also two different types of adsorption modes for 3,4-DMT, $\eta^{1}(\mathrm{~S})$ and $\eta^{2}(\mathrm{CC})$, are shown in Figs. $4 \mathrm{a}$ and $4 \mathrm{~b}$, respectively. The BSSE corrected $\eta^{1}(\mathrm{~S})$ adsorption energy of 3,4 -DMT is calculated to be $-63.90 \mathrm{~kJ} / \mathrm{mol}$, which is $4.32 \mathrm{~kJ} / \mathrm{mol}$ lower than the $\eta^{2}$ (CC) adsorption energy of $-68.22 \mathrm{~kJ} / \mathrm{mol}$. There is an obvious $\mathrm{H}$-bond in the optimized structure of $\eta^{1}(\mathrm{~S})$ adsorption mode with the $\mathrm{S}-\mathrm{H}$ bond distance of $2.10 \AA$. However, the S-H bond strength is much weaker in the $\eta^{2}(\mathrm{CC})$ mode because of the longer S-H bond of $2.88 \AA$. It is different from the 3,4-DMT case that two adsorption modes of BT are $\eta^{1}(\mathrm{~S})$ and $\eta^{2}(\mathrm{SC})$, are shown in Figs. $4 \mathrm{c}$ and $4 \mathrm{~d}$, respectively, and the most stable adsorption mode is not $\eta^{1}(\mathrm{~S})$, but $\eta^{2}(\mathrm{SC})$. The calculated adsorption energy of $\eta^{2}(\mathrm{SC})$ is $-84.18 \mathrm{~kJ} / \mathrm{mol}$, higher than the $\eta^{1}(\mathrm{~S})$ adsorption energy of -69.73 $\mathrm{kJ} / \mathrm{mol}$. In the optimized structure of $\eta^{2}$ (SC) adsorption mode of BT, the distances of zeolite acidic proton $\mathrm{H}$ to $\mathrm{S}$ and $\mathrm{C}_{\alpha}$ are 2.50 and $2.57 \AA$, respectively.

The subsequent thiophenic ring cracking reactions of 3,4-DMT and BT are similar to that of thiophene, and the activation barriers energy are $375.85 \mathrm{~kJ} / \mathrm{mol}$ and $380.30 \mathrm{~kJ} / \mathrm{mol}$, respectively. The calculated ONIOM energy components in terms of QM and MM contributions of transition states are listed in Table 1. As expected, the MM contributions are positive, which reflects again that the zeolite environments could not stabilize the transition state structures. From Table 1, compared with the thiophene case, the difference of activation energies indicates that electron-donating group could contribute to decrease the activation energy of the thiophenic ring cracking. However, the energy barriers are still too high for the occurrence of $\mathrm{C}-\mathrm{S}$ bond cracking step at room temperature. The optimized transition state structures of TS-2CH3 and TS-BT are shown in Figs. 5a and 5b, respectively. The $\mathrm{C}-\mathrm{S}$ bonds of TS-2CH3, and TS-BT have been lengthen to 2.50 and $2.34 \AA$ from the complex- $-2 \mathrm{CH}_{3}$ and complex-BT, respectively. Meanwhile, the new $\mathrm{C}-\mathrm{O}$ bond of TS-2CH3 and TS-BT are forming with the distance of 1.89 and $1.70 \AA$, respectively. Interestingly, for the complex-BT, we found another transition state, TS-BT-2 for the cracking step of C-S bond between the phenyl-group and sulfur atom, with the calculated activation barrier of $453.68 \mathrm{~kJ} / \mathrm{mol}$ that is higher than that for the TS-BT $(380.30 \mathrm{~kJ} / \mathrm{mol})$. The corresponding structure of TS-BT-2 is given in SI (Fig. S1(a)).

\subsection{Bimolecular thiophene cracking over H-beta zeolite}

The bimolecular cracking process is a newly emerging mechanism which is 
proposed by Shan, Aksenno, and Chica et al. [18,52-54] This reaction pathway is shown in Scheme 2. Five main steps are involved: (1) protonation of thiophene, (2) co-adsorption of the second thiophene molecule in the channel of H-beta zeolite, (3) dimerization of the co-adsorbed thiophene molecules, (4) deprotonation of the dimerized thiophene, and (5) $\mathrm{C}-\mathrm{S}$ bond cleavage and ring-opening of the dimerized complex molecule by further protonation step.

Firstly, the adsorbed thiophene molecule (complex-TH-1, $\eta^{2}(\mathrm{CC})$ mode) is protonated to form the INT-TH-2 through transition state, TS-TH-2, with the activation barrier of $69.89 \mathrm{~kJ} / \mathrm{mol}$. The second thiophene is then co-adsorbed with the first protonated thiophene (complex-TH-2) with the BSSE-corrected co-adsorption energy of $-86.03 \mathrm{~kJ} / \mathrm{mol}$. Subsequently, the complex-TH-2 undergoes an electrophilic aromatic substitution step to produce the intermediate INT-TH-3. The corresponding transition state is TS-TH-3 and this process needs to overcome an activation barrier of $88.66 \mathrm{~kJ} / \mathrm{mol}$. The resulting INT-TH-3 is deprotonated through TS-TH-4 with an activation barrier of $29.99 \mathrm{~kJ} / \mathrm{mol}$ and complex-TH-3 is produced, enabling further $\mathrm{C}-\mathrm{S}$ bond cracking reactions. Finally, it should be mentioned that Li et al. reported that in H-ZSM-5 zeolite, the complex-TH-3 could be formed via a collaborative dimerization step of two co-adsorbed thiophene molecules with the energy barrier of $101 \mathrm{~kJ} / \mathrm{mol}$. Our calculations suggested that the formation of complex-TH-3 should occur through a stepwise mechanism, not concerted one.

Figs. 6 and 7 give the geometrical structures of all the transition states and intermediates involved in bimolecular mechanism. At the TS-TH-2 in Fig. 6, the thiophene is almost protonated with the $\mathrm{C}_{\alpha}-\mathrm{H}$ bond length of $1.14 \AA$. Interestingly, for the complex-TH-1, we found another transition state, TS-TH-2' for the protonation step of thiophene molecule at the $\mathrm{C}_{\beta}$ position, with the calculated activation barrier of $96.82 \mathrm{~kJ} / \mathrm{mol}$ that is higher than that for the TS-TH-2 at the $\mathrm{C}_{\alpha}$ position $(69.89 \mathrm{~kJ} / \mathrm{mol})$. The corresponding structure of TS-TH-2' is given in SI (Fig. S1(b)). In the TS-TH-3, the distance between the two bonding carbon atoms (C4-C5) is $1.83 \AA$. After the TS-TH-4, the $\mathrm{H}$ atom in $\mathrm{C} 5-\mathrm{H}$ bond of the second thiophene ring migrates back into the nearby acid site. The complex-TH-3 is then formed with Oa-H distance of $1.01 \AA$ and the Brønsted acid site is regenerated.

Complex-TH-3 can be converted into INT-TH-4 through a transition state, TS-TH-5. At the TS-TH-5 presented in Fig. 7c, the $\mathrm{C}-\mathrm{S}$ bond of the active thiophene moiety is lengthened to $2.79 \AA$ and its $\mathrm{S}$ atom is protonated by the nearby acid site with the $\mathrm{S}-\mathrm{H}$ bond distance of $1.36 \AA$. The newly formed $\mathrm{C}-\mathrm{O}$ bond length in 
INT-TH-4 is $1.55 \AA$. The corresponding activation barrier is calculated to be 139.35 $\mathrm{kJ} / \mathrm{mol}$, which is obviously lower than that of the $\mathrm{C}-\mathrm{S}$ bond creaking step of unimolecular thiophene mentioned above $(426.89 \mathrm{~kJ} / \mathrm{mol})$, indicating that thiophene cracking process over H-beta zeolite should occur preferably via bimolecular mechanism. A close analysis of the energy components in Table 2 indicates that the zeolite framework generally could stabilize the transition states of bimolecular mechanisms because of the negative MM contributions.

\subsection{Unimolecular thiophene cracking over M-beta zeolite}

In this section, the influence of metal cations such as $\mathrm{Li}^{+}, \mathrm{Na}^{+}, \mathrm{K}^{+}, \mathrm{Cu}^{+}$, and $\mathrm{Ag}^{+}$, on the cracking mechanism of thiophene over Beta zeolite will be discussed. As we know, the participation of $\mathrm{H}_{2}$ molecules will make the formation of Brønsted acid sites possible, and the presence of both acidic sites and metal cations must deeply complicate the desulfurization mechanism of thiophene. Therefore, for convenience, we only pay our attention to the cracking mechanism in the absence of $\mathrm{H}_{2}$ molecules, as shown in scheme 3. Furthermore, only the metal cation near the acidic sites be investigated, although metal cations can be located in different positions with their different stabilities [22], and the behavior of inactive metal cations will not be studied.

In the optimized structures of five different metal cation-exchanged pure zeolites $\left(\mathrm{Li}^{+}, \mathrm{Cu}^{+}, \mathrm{Ag}^{+}, \mathrm{Na}^{+}\right.$, and $\left.\mathrm{K}^{+}\right)$, it is notable that there are two weak bonds, $\mathrm{M} \cdots \mathrm{Oa}$ and $\mathrm{M} \cdots \mathrm{Ob}$. Although these two weak bonds have about the same bond lengths, M⿻Oa is relatively shorter slightly than $\mathrm{M} \cdots \mathrm{Ob}$. The almost symmetric binding between the alkali-metal and $\left[\mathrm{AlO}_{4}\right]^{-}$group has been confirmed by an ESR experiment [55]. The order of the average distance of metal cation to acidic zeolite oxygen atoms $\mathrm{Oa}$ (or $\mathrm{Ob}$ ) is $\mathrm{Li}^{+}<\mathrm{Cu}^{+}<\mathrm{Na}^{+}<\mathrm{Ag}^{+}<\mathrm{K}^{+}$, which is consistent with previous theoretical studies $[24,56]$.

The general reaction pathway of unimolecular thiophene cracking over M-beta is shown in Scheme 3E. First, similar to the case of H-beta, one thiophene is adsorbed in the channel of M-beta, forming complex-M-1. Except the $\mathrm{K} \cdots \mathrm{Ob}$, the weak bonds, $\mathrm{M} \cdots \mathrm{Oa}$ and $\mathrm{M} \cdots \mathrm{Ob}$ in all complex-M-1 structures are slightly lengthened relative to those in pure M-beta zeolites (Figs. 8a and 8b). There are two types of adsorption modes, $\eta^{1}(\mathrm{~S})$ and $\eta^{5}$ over Li- and K-beta, and the most stable adsorption structure is $\eta^{5}$. For the $\eta^{5}$ mode, metal cations interact with thiophene ring. Interestingly, over Na-, $\mathrm{Cu}$-, and Ag-beta, two modes, $\eta^{1}(\mathrm{~S})$ and $\eta^{2}(\mathrm{CC})$ exist, and the most stable adsorption structure is $\eta^{2}(\mathrm{CC})$. The optimized adsorption modes over Li- and Na-beta are shown 
in Figs. 8c and 8d, respectively. The BSSE corrected adsorption energies of thiophene in M-beta are $-89.03,-81.26,-71.72,-135.41$, and $-113.04 \mathrm{~kJ} / \mathrm{mol}$ for $\mathrm{M}=\mathrm{Li}^{+}, \mathrm{Na}^{+}$, $\mathrm{K}^{+}, \mathrm{Cu}^{+}$, and $\mathrm{Ag}^{+}$, respectively. The higher adsorption energy in $\mathrm{Cu}$-beta than that in $\mathrm{Ag}$-beta is consistent with experimental result in cation-exchanged FAU zeolite [57].

Complex-M-1 undergoes $\mathrm{C}-\mathrm{S}$ bond cracking through transition state, TS-M-1, to form the intermediate, INT-M-1. Because the optimized geometrical parameters of TS-M-1 and INT-M-1 for different metal cations are similar, we selected the structures over Li-beta as a representative example, as given in Figs. 9a and 9b. In TS-Li-1, it can be found that the $\mathrm{C}-\mathrm{S}$ bond is clearly broken, and the distances of $\mathrm{Li}-\mathrm{S}, \mathrm{C}-\mathrm{S}, \mathrm{C}-\mathrm{Ob}$ are $2.32 \AA, 2.46 \AA, 1.71 \AA$, respectively. After the TS-Li-1, the INT-Li-1 is formed with the shorter $\mathrm{C}-\mathrm{Ob}$ and Li-S bond distances in Fig. 9b. The activation barrier of this cracking step is $453.32 \mathrm{~kJ} / \mathrm{mol}$. In Na-, K-, Cu-, and Ag-beta, the corresponding energy barriers are 424.16, 419.66, 388.84, and $414.62 \mathrm{~kJ} / \mathrm{mol}$, respectively. Therefore, compared to that of TS-TH-1 $(426.89 \mathrm{~kJ} / \mathrm{mol})$ in H-beta, it can be concluded that the metal cations could not decrease the difficulty of the unimolecular $\mathrm{C}-\mathrm{S}$ bond cracking step more effectively. Table 3 lists the energy decompositions in QM and MM contributions for TS-M-1. Similar to the case of thiophene in H-beta, the MM contributions are all positive, reflecting that the cation-exchanged zeolite frameworks disfavor the unimolecular C-S bond cracking reactions.

\subsection{Bimolecular thiophene cracking over M-beta zeolite}

The bimolecular thiophene cracking process of thiophene over M-beta is shown in Scheme 3F; this pathway is different from bimolecular thiophene cracking over H-beta. It starts with two thiophene molecules adsorbed in the channel of the zeolite (complex-M-2). Surprisingly, the transition state structure of dimerization step is different from that in H-beta. For example, in the optimized geometrical parameters of TS-Li-2 given in Fig. 10a, the $\mathrm{H}$ atom belonging to $\mathrm{C} 1$ of the first thiophene is transferring to the $\mathrm{C} 8$ of the second thiophene, while the $\mathrm{C} 5$ is attacking $\mathrm{C} 1$ forming the complex-Li-3. The distance of $\mathrm{C} 1-\mathrm{H}, \mathrm{C} 8-\mathrm{H}, \mathrm{C} 5-\mathrm{C} 1$ in TS-Li-2 are 1.30, 1.59, and $1.81 \AA$, respectively. The activation barriers of this step over $\mathrm{Li}-, \mathrm{Na}-, \mathrm{K}-, \mathrm{Cu}-$, and Ag-beta are 232.56, 256.52, 250.49, 226.24, and $258.54 \mathrm{~kJ} / \mathrm{mol}$, respectively. The higher energy barriers than that for dimerization step of two thiophene in H-beta $(88.66 \mathrm{~kJ} / \mathrm{mol})$ suggest that the occurrence of polymerization process in M-Beta zeolite is unfavorable. Subsequently, the C-S bond cleavage of complex-Li-3 takes 
place through the transition state, TS-Li-3, shown in Fig. 10c. At TS-Li-3, the S-C5 bond is broken and the $\mathrm{S}$ atom is weakly bonded to $\mathrm{Li}^{+}$cation; the distances of $\mathrm{S}-\mathrm{C} 5$ and $\mathrm{Li}-\mathrm{S}$ are 3.04 and $2.37 \AA$, respectively. The corresponding activation barriers of this C-S bond cracking step over Li-, Na-, K-, Cu-, and Ag- are 171.04, 229.33, $268.35,136.08$, and $176.76 \mathrm{~kJ} / \mathrm{mol}$, respectively, generally higher than that in H-beta zeolite $(139.35 \mathrm{~kJ} / \mathrm{mol})$. Although the energy barrier over $\mathrm{Cu}$-beta is relatively lower, the bimolecular mechanism is still unfavorable due to the high energy barrier of dimerization step $(226.24 \mathrm{~kJ} / \mathrm{mol})$ mentioned above. All energy data of bimolecular mechanisms are given in Table 4 .

\section{Conclusion}

We have performed a two-layer ONIOM study on the unimolecular and bimolecular mechanisms of thiophene cracking catalyzed by acidic and metal cation-exchanged $\left(\mathrm{Li}^{+}, \mathrm{Na}^{+}, \mathrm{K}^{+}, \mathrm{Cu}^{+}\right.$, and $\left.\mathrm{Ag}^{+}\right)$beta zeolites. The unimolecular cracking mechanisms of 3,4-dimethylthiophene (3,4-DMT) and benzothiophene (BT) over the acidic beta zeolite are also investigated to reveal the effect of electron-donating group.

Our calculations suggests that in acidic zeolite, the bimolecular cracking mechanism of thiophene is more favorable than unimolecular mechanism due to lower activation barrier. The rate-determining steps for these two mechanisms are both C-S bond cracking step. For 3,4-DMT and BT, the effect of electron-donating group is negligible because of still high energy barriers. In M-beta zeolite, the activation barriers of bimolecular mechanisms are lower than those of unimolecular ones, but still higher than those of bimolecular thiophene cracking in H-beta, indicating that the metal cations do not reduce and contrarily increase their difficulty of thiophene cracking reactions.

A comparison of adsorption energy of thiophene between H-beta and M-beta zeolites suggests that thiophene molecules can be adsorbed more strongly in M-beta zeolite. In consideration of the above-mentioned inability of metal cations in reducing the difficulty of thiophene cracking process in H-beta, the adsorptive desulfurization would be a potential choice for cation-exchanged zeolites due to the higher adsorption energies, which is consistent with experimental observations.

Decomposing ONIOM energy into QM and MM contributions is an important way to investigate the effect of the zeolite environment on the reaction pathways. The activation barrier data suggest that in H-beta zeolite, the MM energy values are 
positive for the unimolecular step but negative for bimolecular step, indicating that the zeolite framework can stabilize the transition states of bimolecular mechanism. In M-beta zeolites, the zeolite environment generally disfavor the thiophene cracking mechanisms.

\section{Acknowledgment}

This work was funded by the National Science Foundation of China (nos. 21203118), the Innovation Program of Shanghai Municipal Education Commission (grant 14YZ147), and the Training Program for Young College Teachers in Shanghai (ZZyyy12005).

\section{Appendix A. Supplementary material}

$S$ values (in Hartrees) calculated for several representative transition state structures, optimized structures of TS-M-1, TS-M-2, and TS-M-3 $\left(\mathrm{M}=\mathrm{Na}^{+}, \mathrm{K}^{+}, \mathrm{Cu}^{+}\right.$, and $\mathrm{Ag}^{+}$), the atomic coordinates of all the optimized structures involved in Figures 2-10 are provided.

\section{References}

[1] C.S. Song, X.L. Ma, New design approaches to ultra-clean diesel fuels by deep desulfurization and deep dearomatization, Appl. Catal. B 41 (2003) 207-238.

[2] B. Pawelec, R.M. Navarro, J.M. Campos-Martin, J.L.G. Fierro, Towards near zero-sulfur liquid fuels: a perspective review, Catal. Sci. Technol. 1 (2011) 23-42.

[3] J. Xiao, X.-X. Wang, M. Fujii, Q. Yang, C.-S. Song, A novel approach for ultra-deep adsorptive desulfurization of diesel fuel over $\mathrm{TiO}_{2}-\mathrm{CeO}_{2} / \mathrm{MCM}-48$ under ambient conditions, AIChE J. 59 (2013) 1441-1445.

[4] X.-L. Ma, L. Sun, C.-S. Song, A new approach to deep desulfurization of gasoline, diesel fuel and jet fuel by selective adsorption for ultraclean fuels and for fuel cell applications, Catal. Today, 77 (2002) 107-116.

[5] H.-L. Yin, T.-N. Zhou, Y.-Q. Liu, Y.-M. Chai, C.-G. Liu, $\mathrm{NiMo} / \mathrm{Al}_{2} \mathrm{O}_{3}$ catalyst containing nano-sized zeolite $\mathrm{Y}$ for deep hydrodesulfurization and hydrodenitrogenation of diesel, J. Nat. Gas. Chem. 20 (2011) 441-448.

[6] J.R. Anderson, M. Boudart, (Eds.), Catalysis, science and technology, Springer-Verlag, Berlin, 1996, vol. 11.

[7] C. -S. Song, An overview of new approaches to deep desulfurization for ultra-clean gasoline, diesel fuel and jet fuel, Catal. Today 86 (2003) 211-263. 
[8] D.D. Whitehurst, T. Isoda, I. Mochida, Present state of the art and future challenges in the hydrodesulfurization of polyaromatic sulfur compounds, Adv. Catal. 42 (1998) 345-471.

[9] M. Toba, Y. Miki, Y. Kanda, T. Matsui, M. Harada, Y. Yoshimura, Selective hydrodesulfurization of FCC gasoline over $\mathrm{CoMo} / \mathrm{Al}_{2} \mathrm{O}_{3}$ sulfide catalyst, Catal. Today 104 (2005) $64-69$.

[10] J.A. Valla, A.A. Lappas, I.A. Vasalos, C.W. Kuehler, N.J. Gudde, Feed and process effects on the in situ reduction of sulfur in FCC gasoline, Appl. Catal. A 276 (2004) 75-87.

[11] C.L. Garcia, J.A. Lercher, Adsorption and surface reactions of thiophene on ZSM5 zeolites, J. Phys. Chem. 96 (1992) 2669-2675.

[12] C.L. Garcia, J.A. Lercher, Hydrogen bonding of sulfur containing compounds adsorbed on zeolite HZSM5, J. Mol. Struct. 293 (1993) 235-238.

[13] W.J.J. Welters, G. Vorbeck, H.W. Zandbergen, J.W. Dehaan, V.H.J. Debeer, R. A. Vansanten, HDS activity and characterization of zeolite-supported nickel sulfide catalysts, J. Catal. 150 (1994) 155-169.

[14] S.-Y. Yu, W. Li, E. Iglesia, Desulfurization of thiophene via hydrogen transfer from alkanes on cation-modified H-ZSM5, J. Catal. 187 (1999) 257-261.

[15] S.-Y. Yu, J. Garcia-Martinez, W. Li, G.D. Meitznerb, E. Iglesia, Kinetic, infrared, and X-ray absorption studies of adsorption, desorption, and reactions of thiophene on H-ZSM5 and Co/H-ZSM5, Phys. Chem. Chem. Phys. 4 (2002) 1241-1251.

[16] W.J.J. Welters, V.H.J. de Beer, R.A. van Santen, Influence of zeolite acidity on thiophene hydrodesulfurization activity, Appl. Catal. A 119 (1994) 253-269.

[17] B.A. de Angelis, G. Appierto, Infrared spectroscopic study of thiophene adsorbed on zeolites, J. Colloid Interface Sci. 53 (1975) 14-19.

[18] H.-H. Shan, C.-Y. Li, C.-H. Yang, H. Zhao, B.-Y. Zhao, J.-F. Zhang, Mechanistic studies on thiophene species cracking over USY zeolite, Catal. Today 77 (2002) 117-126.

[19] Y.-J. Gong, T. Dou, S.-J. Kang, Q. Li, Y.-F. Hu, Deep desulfurization of gasoline using ion-exchange zeolites: $\mathrm{Cu}(\mathrm{I})$ - and $\mathrm{Ag}(\mathrm{I})$ - beta, Fuel Process. Technol. 90 (2009) 122-129.

[20] X. Saintigny, R.A. van Santen, S. Clémendot, F. Hutschka, A theoretical study of the solid acid catalyzed desulfurization of thiophene, J. Catal. 183 (1999) 107-118.

[21] X. Rozanska, R.A. van Santen, F. Hutschka, A DFT study of the creaking reaction of thiophene activated by small zeolitic clusters, J. Catal. 200 (2001) 79-90.

[22] X. Rozanska, R.A. van Santen, F. Hutschka, J. Hafner, A periodic density functional theory study of thiophenic derivative cracking catalyzed by mordenite, J. Catal. 215 (2003) 20-29.

[23] B.-R. Li, W.-P. Guo, S.-P. Yuan, J. Hu, J. G. Wang, H.-J. Jiao, A theoretical investigation into the thiophene-cracking mechanism over pure Brønsted acidic zeolites, J. Catal. 253 (2008) 
$212-220$.

[24] D. Lee, J. Kim, H.-C. Lee, K.-H. Lee, E.-D. Park, H.-C. Woo, Adsorption properties of organosulfur compounds on zeolite clusters: A density functional theory calculation study, J. Phys. Chem. C 112 (2008) 18955-18962.

[25] M. Boronat, P.M. Viruela, A. Corma, Reaction intermediates in acid catalysis by zeolites: prediction of the relative tendency to form alkoxides or carbocations as a function of hydrocarbon nature and active site structure, J. Am. Chem. Soc. 126 (2004) 3300-3309.

[26] V. Nieminen, M. Sierka, D.Y. Murzin, J. Sauer, Stabilities of $\mathrm{C}_{3}-\mathrm{C}_{5}$ alkoxide species inside H-FER zeolite: a hybrid QM/MM study, J. Catal. 231 (2005) 393-404.

[27] Y.V. Joshi, K.T. Thomson, Embedded cluster (QM/MM) investigation of C6 diene cyclization in HZSM-5, J. Catal. 230 (2005) 440-463.

[28] T. Vreven, K. Morokuma, On the application of the IMOMO (integrated molecular orbital + molecular orbital) method, J. Comput. Chem. 21 (2000) 1419-1432.

[29] T. Vreven, B. Mennucci, C.O. da Silva, K. Morokuma, J. Tomasi, The ONIOM-PCM method: Combining the hybrid molecular orbital method and the polarizable continuum model for solvation. Application to the geometry and properties of a merocyanine in solution, J. Chem. Phys. 115 (2001) 62-72.

[30] T. Vreven, K.S. Byun, I. Komaromi, S. Dapprich, J.A. Montgomery, K. Morokuma, M.J. Frisch, Combining quantum mechanics methods with molecular mechanics methods in ONIOM, J. Chem. Theory Comput. 2 (2006) 815-826.

[31] J.M. Newsam, M.M.J. Treacy, W.T. Koetsier, C.B. de Gruyter, Structural characterization of zeolite beta, Proc. R. Soc. Lond. A 420 (1988) 375-405.

[32] Y. -X. Sun, S. Han, Mechanistic investigation of methanol to propene conversion catalyzed by H-beta zeolite: a two-layer ONIOM study, J. Mol. Model. 19 (2013) 5407-5422.

[33] T. Maihom, B. Boekfa, J. Sirijaraensre, T. Nanok, M. Probst, J. Limtrakul, Reaction mechanisms of the methylation of ethene with methanol and dimethyl ether over H-ZSM-5: an ONIOM study, J. Phys. Chem. C 113 (2009) 6654-6662.

[34] S. Svelle, C. Tuma, X. Rozanska, T. Kerber, J. Sauer, Quantum chemical modeling of zeolite-catalyzed methylation reactions: toward chemical accuracy for barriers, J. Am. Chem. Soc. 131 (2009) 816-825.

[35] F. Maseras, K. Morokuma, IMOMM: A new integrated ab initio + molecular mechanics geometry optimization scheme of equilibrium structures and transition states, J. Comput. Chem. 16 (1995) 1170-1179.

[36] K. Morokuma, ONIOM and its applications to material chemistry and catalyses, Bull. Korean Chem. Soc. 24 (2003) 797-801. 
[37] K. Morokuma, D.G. Musaev, T. Vreven, H. Basch, M. Torrent, D.V. Khoroshun, Model studies of the structures, reactivities, and reaction mechanisms of metalloenzymes, IBM J. Res. Dev. 45 (2001) 367-395.

[38] Y. Zhao, N.E. Schultz, D.G. Truhlar, Design of density functionals by combining the method of constraint satisfaction with parametrization for thermochemistry, thermochemical kinetics, and noncovalent interactions, J. Chem. Theory Comput. 2 (2006) 364-382.

[39] Y. Zhao, D.G. Truhlar, Benchmark data for interactions in zeolite model complexes and their use for assessment and balidation of electronic structure methods, J. Phys. Chem. C 112 (2008) 6860-6868.

[40] Y. Zhao, D.G. Truhlar, Density functionals with broad applicability in chemistry, Acc. Chem. Res. 41 (2008) 157-167.

[41] Y. Zhao, D.G. Truhlar, The M06 suite of density functionals for main group thermochemistry, thermochemical kinetics, noncovalent interactions, excited states, and transition elements: two new functionals and systematic testing of four M06-class functionals and 12 other functionals, Theor. Chem. Acc. 120 (2008) 215-241.

[42] A.K. Rappe, C.J. Casewit, K.S. Colwell, W. A. Goddard, III, W. M. Skiff, UFF, a full periodic table force field for molecular mechanics and molecular dynamics simulations, J. Am. Chem. Soc. 114 (1992) 10024-10035.

[43] A. D. Becke, Density-functional thermochemistry. III. The role of exact exchange, J. Chem. Phys. 98 (1993) 5648-5652.

[44] M. Dolg, U. Wedig, H. Stoll, H. Preuss, Ab initio pseudopotential study of the first row transition metal monoxides and iron monohydride, J. Chem. Phys. 86 (1987) 2123-2131.

[45] C. Kumsapaya, K. Bobuatong, P. Khongpracha, Y. Tantirungrotechai, J. Limtrakul, Mechanistic investigation on 1,5- to 2,6-dimethylnaphthalene isomerization catalyzed by acidic $\beta$ zeolite: ONIOM study with an M06-L functional, J. Phys. Chem. C 113 (2009) 16128-16137.

[46] C. Gonzalez, H.B. Schlegel, Reaction path following in mass-weighted internal coordinates, J. Phys. Chem. 94 (1990) 5523-5527.

[47] S. F. Boys, F. Bernardi, The calculation of small molecular interactions by the differences of separate total energies. Some procedures with reduced errors, Mol. Phys. 19 (1970) 553-566.

[48] M. J. Frisch, G.W. Trucks, H.B. Schlegel, G.E. Scuseria, M.A. Robb, J.R. Cheeseman, G. Scalmani, V. Barone, B. Mennucci, G.A. Petersson, H. Nakatsuji, M. Caricato, X. Li, H.P. Hratchian, A.F. Izmaylov, J. Bloino, G. Zheng, J.L. Sonnenberg, M. Hada, M. Ehara, K. Toyota, R. Fukuda, J. Hasegawa, M. Ishida, T. Nakajima, Y. Honda, O. Kitao, H. Nakai, T. Vreven, J. A. Montgomery, Jr., J.E. Peralta, F. Ogliaro, M. Bearpark, J.J. Heyd, E. Brothers, K.N. Kudin, V.N. Staroverov, R. Kobayashi, J. Normand, K. Raghavachari, A. Rendell, J.C. Burant, S.S. Iyengar, J. 
Tomasi, M. Cossi, N. Rega, J.M. Millam, M. Klene, J.E. Knox, J.B. Cross, V. Bakken, C. Adamo, J. Jaramillo, R. Gomperts, R.E. Stratmann, O. Yazyev, A.J. Austin, R. Cammi, C. Pomelli, J.W. Ochterski, R.L. Martin, K. Morokuma, V.G. Zakrzewski, G.A. Voth, P. Salvador, J.J. Dannenberg, S. Dapprich, A.D. Daniels, O. Farkas, J. B. Foresman, J.V. Ortiz, J. Cioslowski, and D.J. Fox, Gaussian, Inc., Wallingford CT, 2009.

[49] X. Li, L. W. Chung, P. Paneth, K. Morokuma, DFT and ONIOM(DFT:MM) studies on Co-C bond cleavage and hydrogen transfer in $\mathrm{B}_{12}$-dependent methylmalonyl-CoA mutase. stepwise or concerted mechanism? J. Am. Chem. Soc. 131 (2009) 5115-5125.

[50] S. Jungsuttiwong, J. Limtrakul, T.N. Truong, Theoretical study of modes of adsorption of water dimmer on H-ZSM-5 and H-Faujasite zeolites, J. Phys. Chem. B 109 (2005) 13342-13351.

[51] D.A. Nichols, J.C. Hargis, R. Sanishvili, P. Jaishankar, K. Defrees, E.W. Smith, K.K. Wang, F. Prati, A.R. Renslo, H.L. Woodcock, Y. Chen, Ligand-induced proton transfer and low-barrier hydrogen bond revealed by X-ray crystallography, J. Am. Chem. Soc. 137 (2015) 8086-8095.

[52] D.G. Aksenov, O.V. Klimov, G.V. Echevskii, E.A. Paukshtis, A.A. Budneva, Thiophene conversion in the BIMF process, React. Kinet. Catal. Lett. 83 (2004) 187-194.

[53] A. Chica, K. Strohmaier, E. Iglesia, Adsorption, desorption, and conversion of thiophene on H-ZSM5, Langmuir 20 (2004) 10982-10991.

[54] A. Chica, K. Strohmaier, E. Iglesia, Effects of zeolite structure and aluminum content on thiophene adsorption, desorption, and surface reactions, Appl. Catal. B 60 (2005) 223-232.

[55] H. Hosono, H. Kawazoe, J. Nishii, J. Kanazawa, Elucidation of the stereochemistry of $\mathrm{Tl}^{+}$in oxide glasses by electron spin resonance spectroscopy, J. Non Cryst. Solid 51 (1982) 217-240.

[56] J. Limtrakul, S. Jungsuttiwong, P. Khongpracha, Adsorption of carbon monoxide on H-FAU and Li-FAU zeolites: an embedded cluster approach, J. Mol. Struct. 525 (2000) 153-162.

[57] R.-T. Yang, A. Takahashi, F.-H. Yang, New sorbents for desulfurization of liquid fuels by $\pi$-complexation, Ind. Eng. Chem. Res. 40 (2001) 6236-6239. 
A:

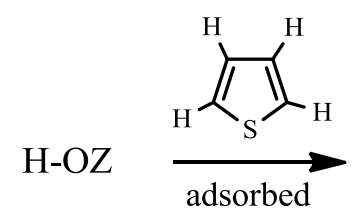<smiles>CC(=O)O[Tl]</smiles>

complex-TH-1

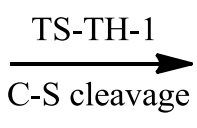

B<smiles>Cc1cc2sccc2cc1CC(=O)O</smiles>

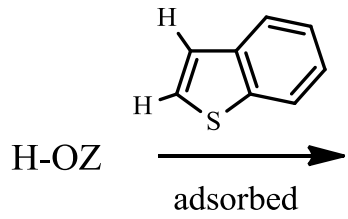

TS-2CH3<smiles>CC(=O)O[Tl]1C=CC(C)=C1</smiles>

complex-2CH3<smiles>C[C@H](Br)C(C)(C)Cl</smiles>

complex-BT<smiles>[C]OC=CC=C</smiles>

INT-TH-1<smiles>[R]OC(=O)/C(C)=C/C</smiles>

INT-2CH3<smiles>CC(=O)/C=C/c1ccccc1S</smiles>

INT-BT

Scheme 1. The cracking reaction pathways of thiophene, 3,4-dimethylthiophene and benzothiophene over H-beta zeolite 

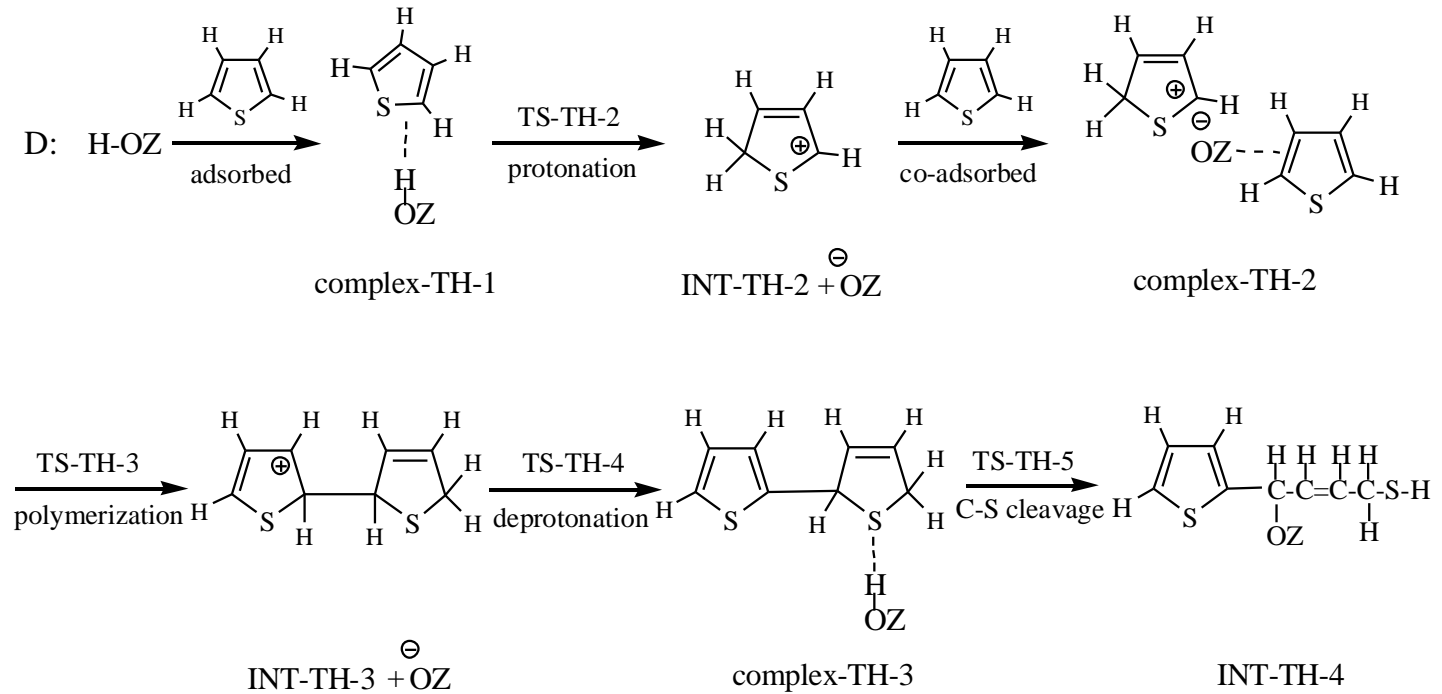

Scheme 2. The bimolecular cracking pathway of thiophene over H-beta zeolite 


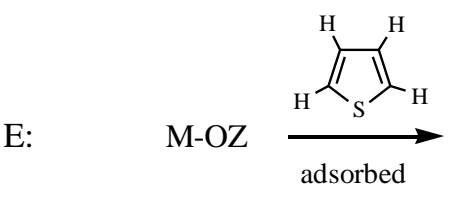

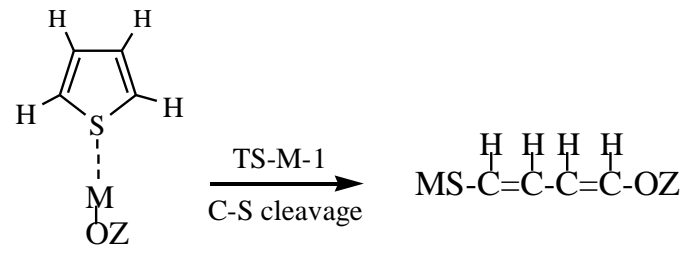

complex-M-1

INT-M-1

F:

complex-M-1

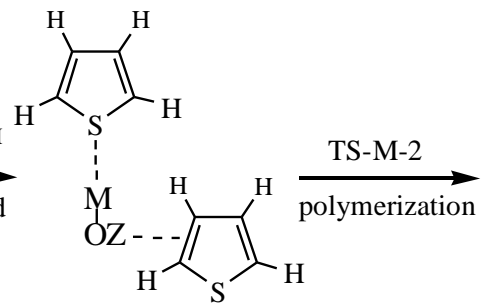

complex-M-2

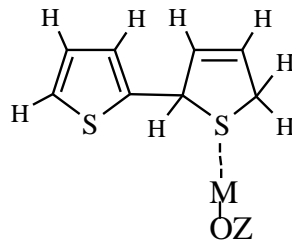

complex-M-3

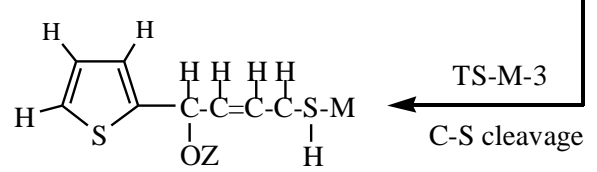

INT-M-2

Scheme 3. Unimolecular and bimolecular cracking pathways of thiophene over $\mathrm{M}$-beta $(\mathrm{M}=$ $\mathrm{Li}^{+}, \mathrm{Na}^{+}, \mathrm{K}^{+}, \mathrm{Cu}^{+}$, and $\mathrm{Ag}^{+}$) zeolites 


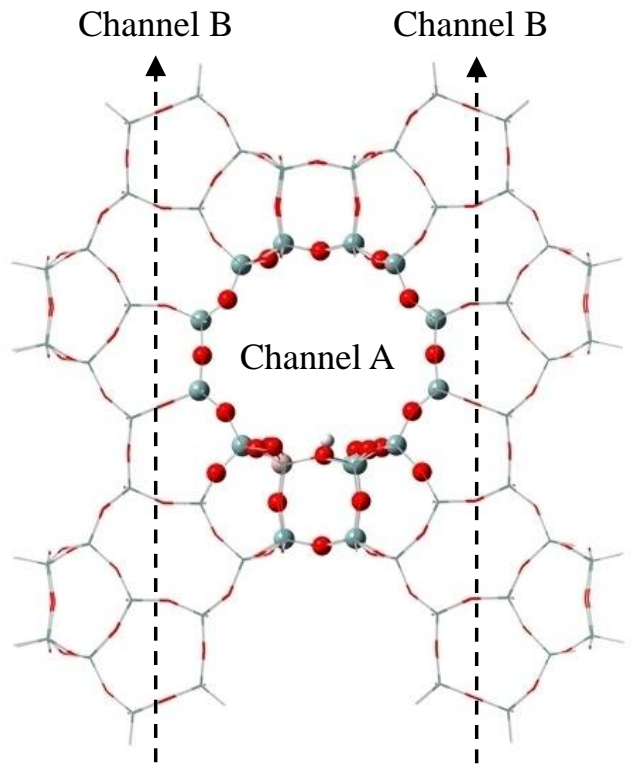

(a)

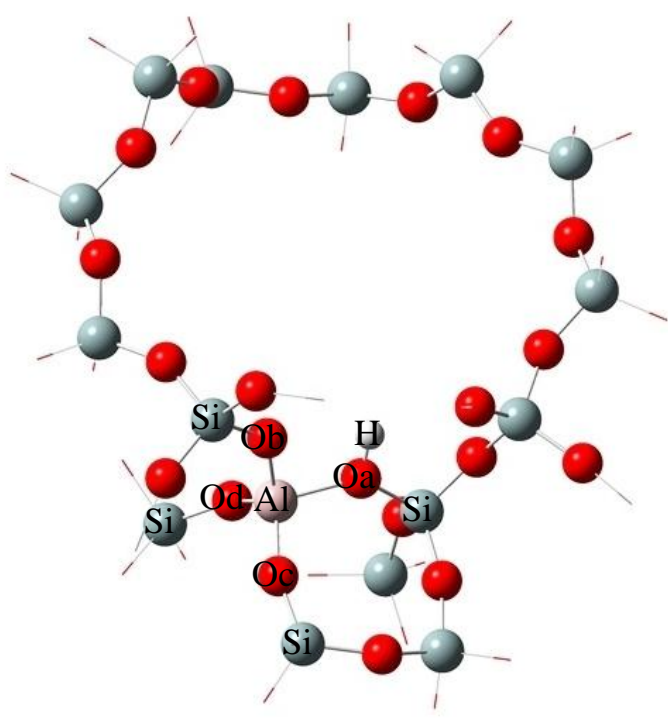

(b)

Figure 1. 188T nanocluster model of H-beta zeolite divided into two areas: the inner 16T region, shown by colored balls, and the outer region by sticks. (a) the whole ONIOM model. (b) the 16T QM region. The dash line indicates the direction of the channel B. 


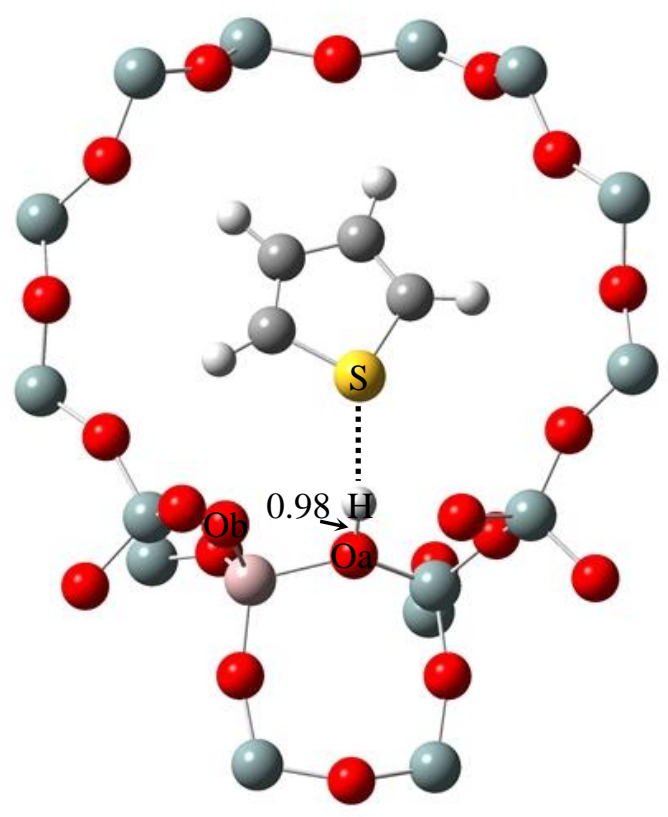

(a)

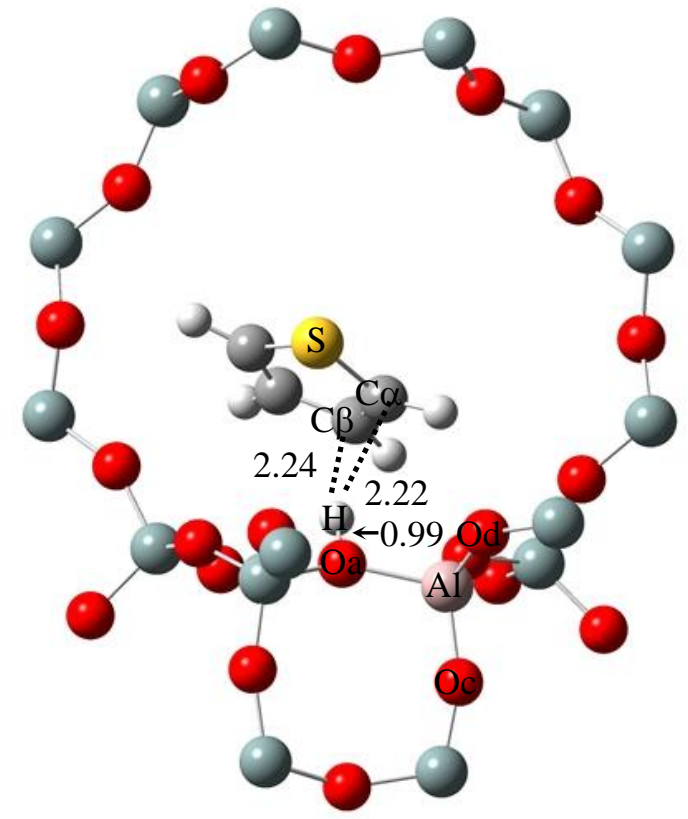

(b)

Figure 2. Optimized structures of complex-TH-1, (a) $\eta^{1}(\mathrm{~S})$ adsorption mode, (b) $\eta^{2}(\mathrm{CC})$ adsorption mode. 


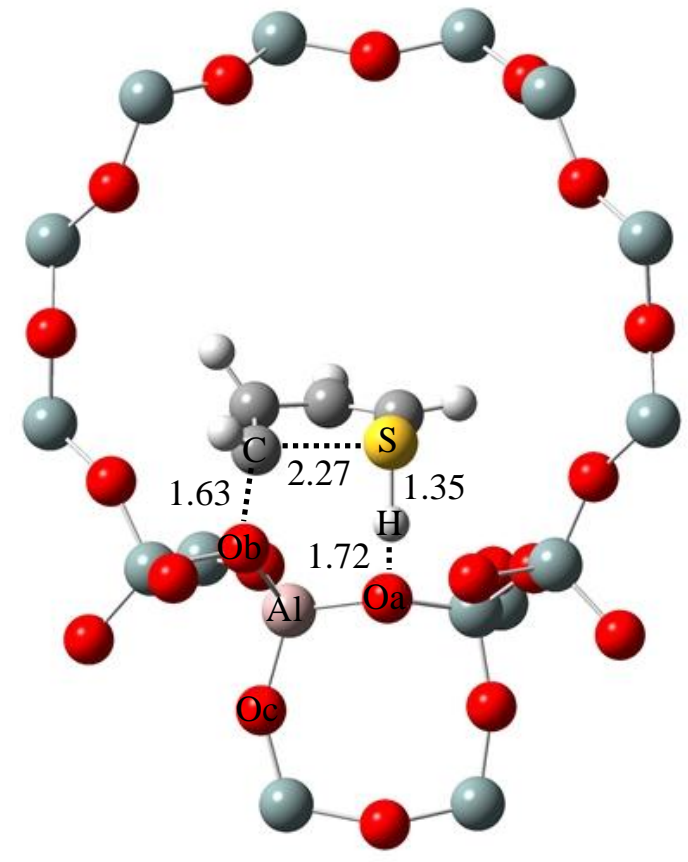

(a)

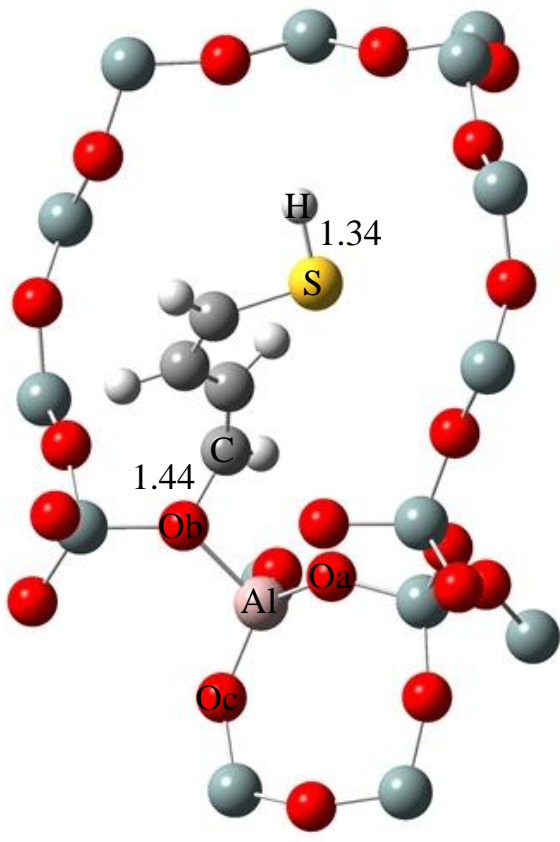

(b)

Figure 3. Optimized structures of (a)TS-TH-1, (b) INT-TH-1. 


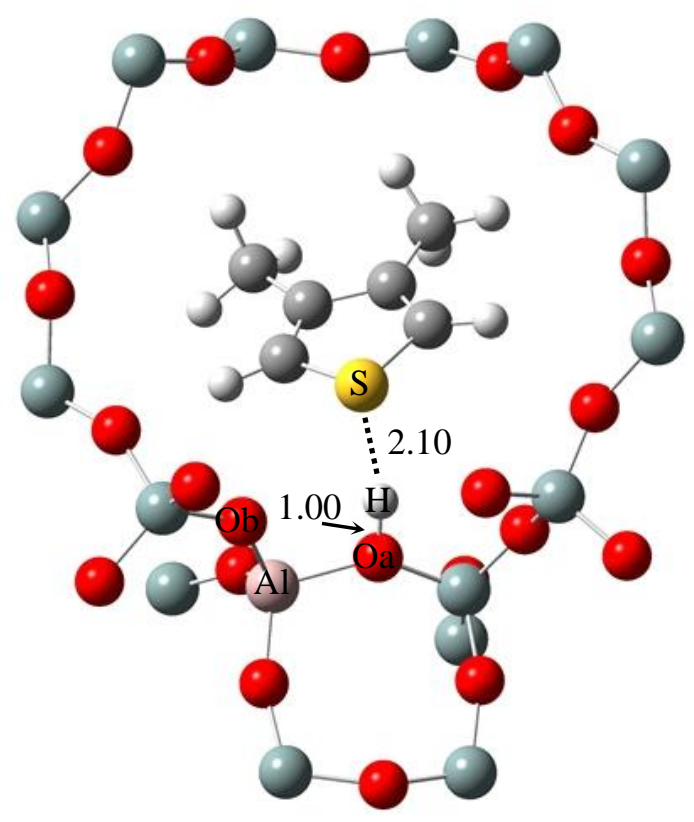

(a)

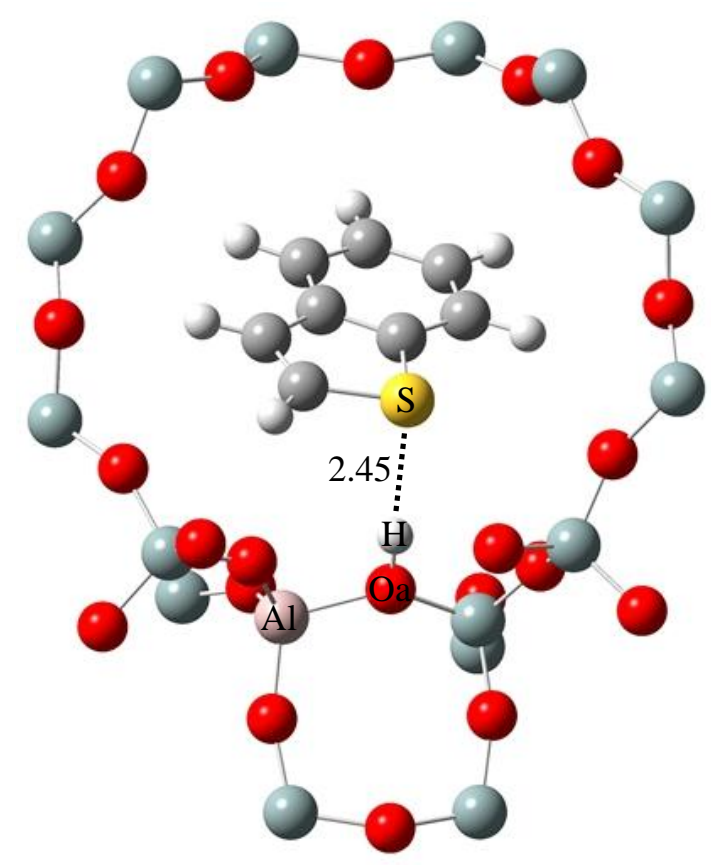

(c)

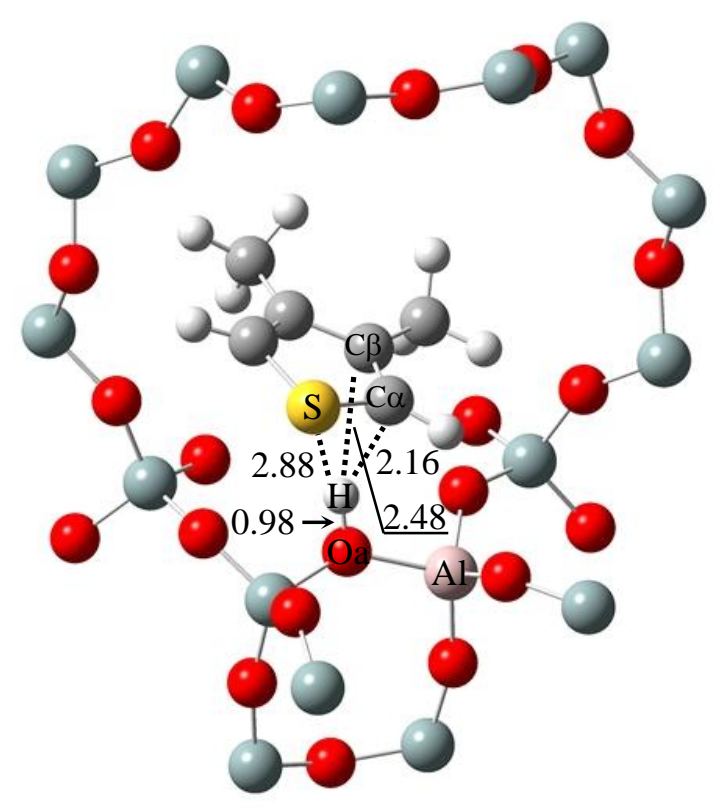

(b)

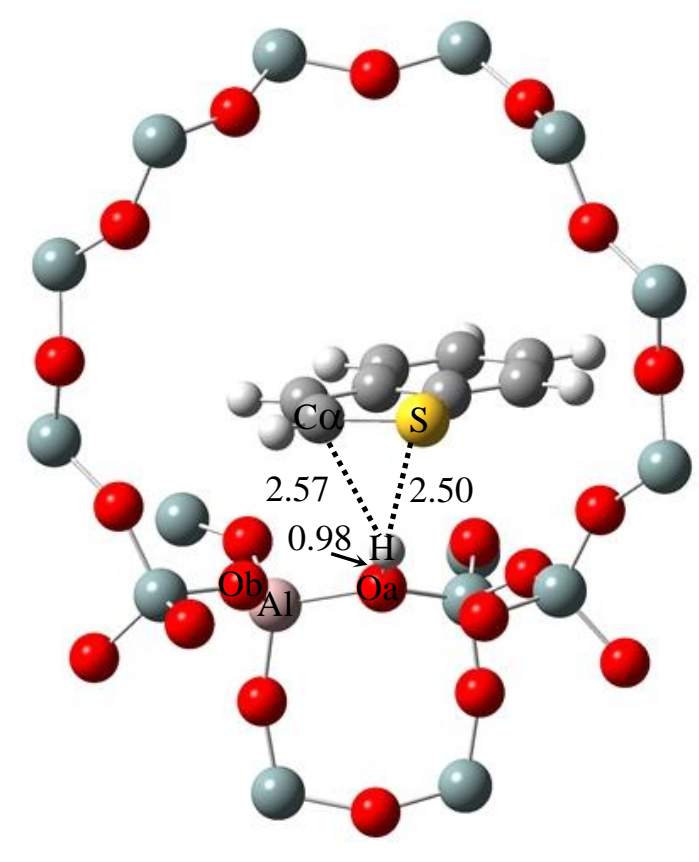

(d)

Figure 4. Optimized structures of complex-2CH3 and complex-BT, (a) $\eta^{1}(\mathrm{~S})$ mode of complex-2CH3, (b) $\eta^{2}(\mathrm{CC})$ mode of complex-2CH3, (c) $\eta^{1}(\mathrm{~S})$ mode of complex-BT, and (d) $\eta^{2}(\mathrm{SC})$ mode of complex-BT. 


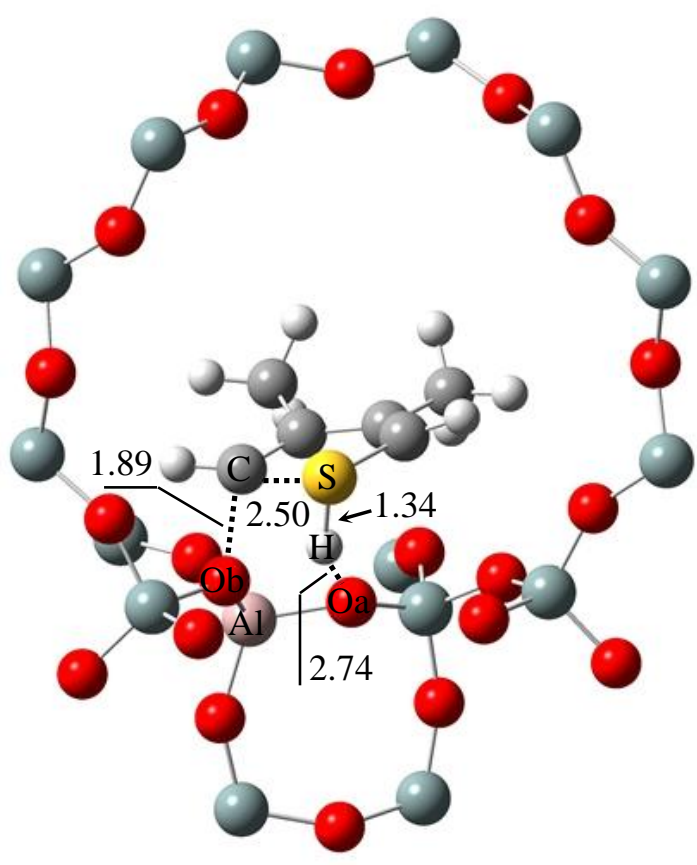

(a)

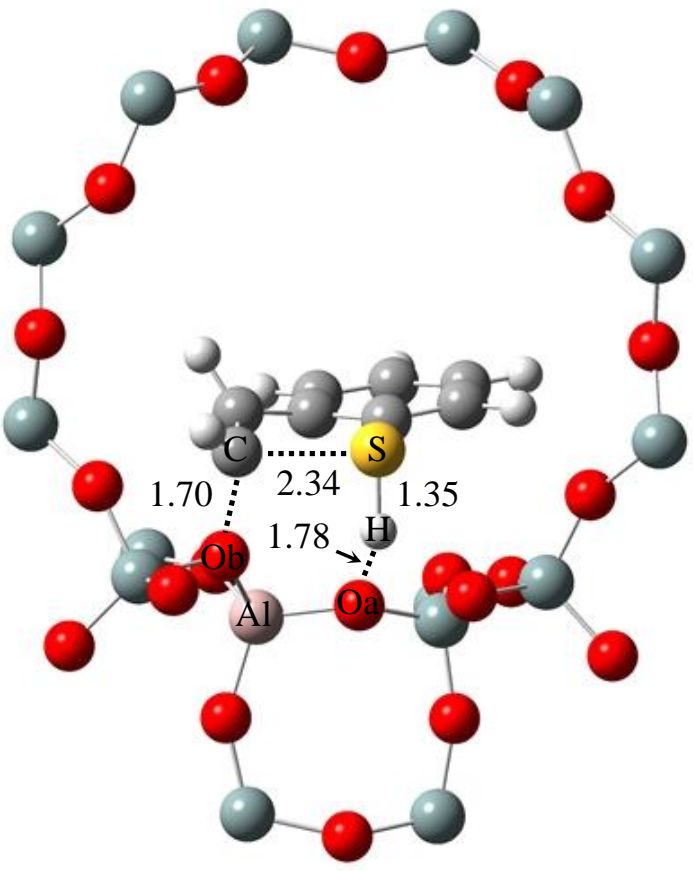

(b)

Figure 5. Optimized structures of transition states, (a) TS-2CH3, and (b) TS-BT. 


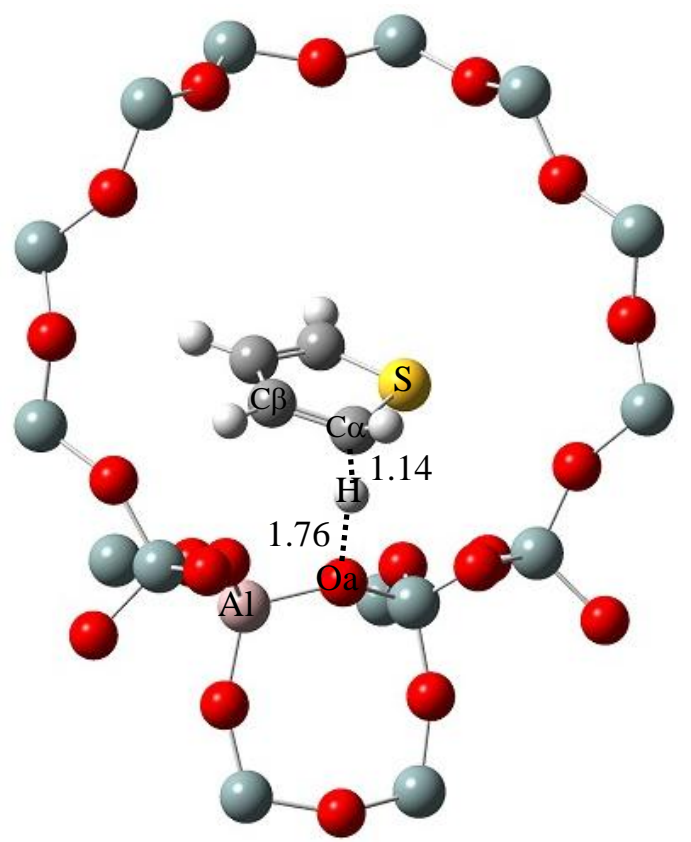

(a)

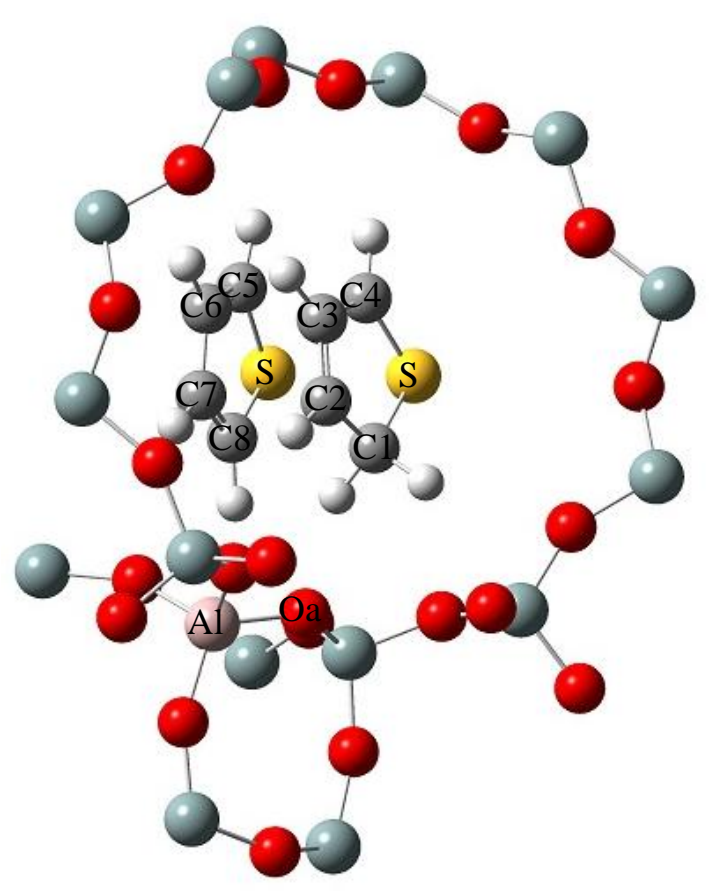

(c)

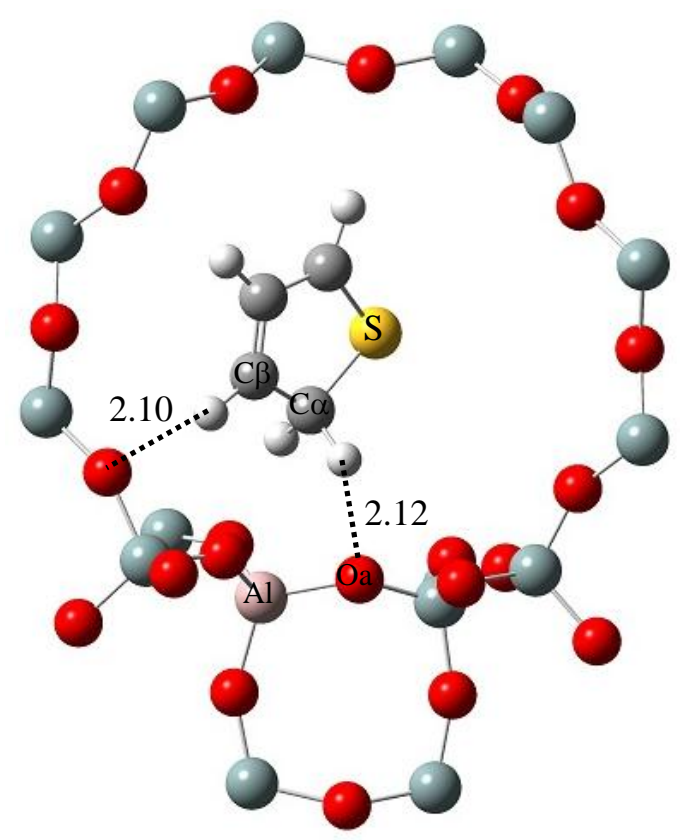

(b)

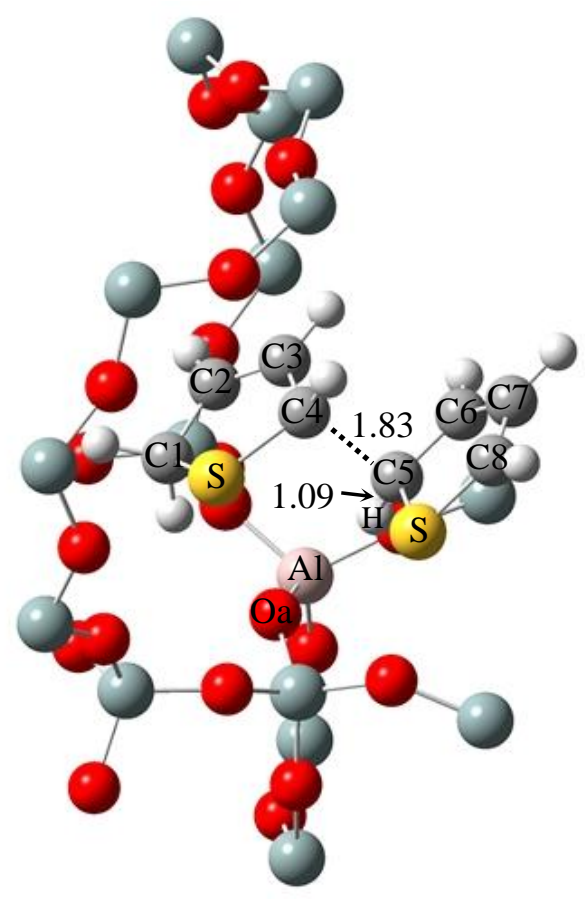

(d) 


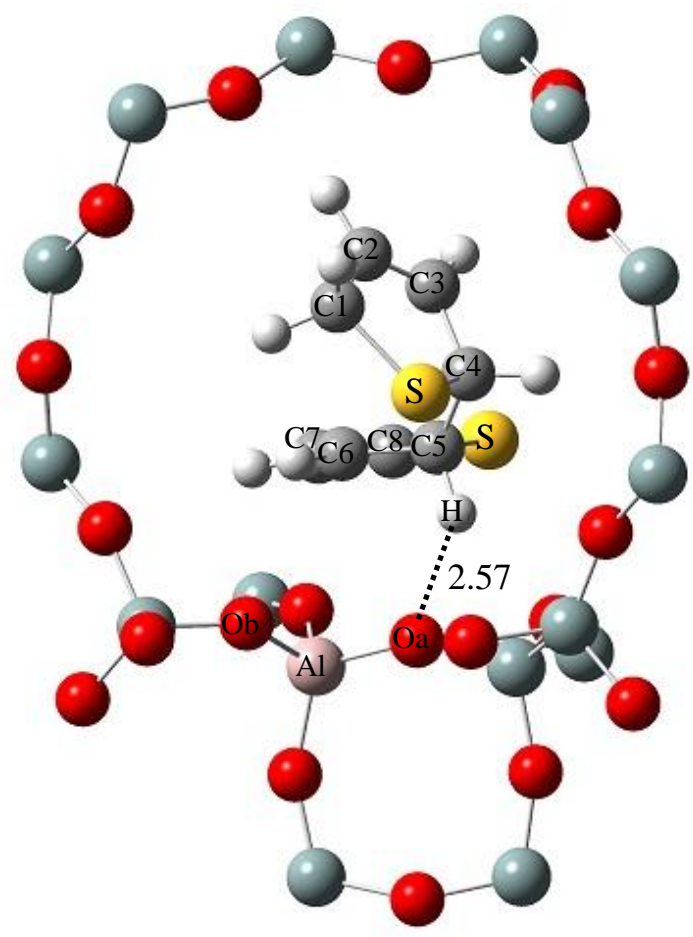

(e)

Figure 6. Optimized structures of (a) TS-TH-2, (b) INT-TH-2, (c) complex-TH-2, (d) TS-TH-3, and (e) INT-TH-3. 


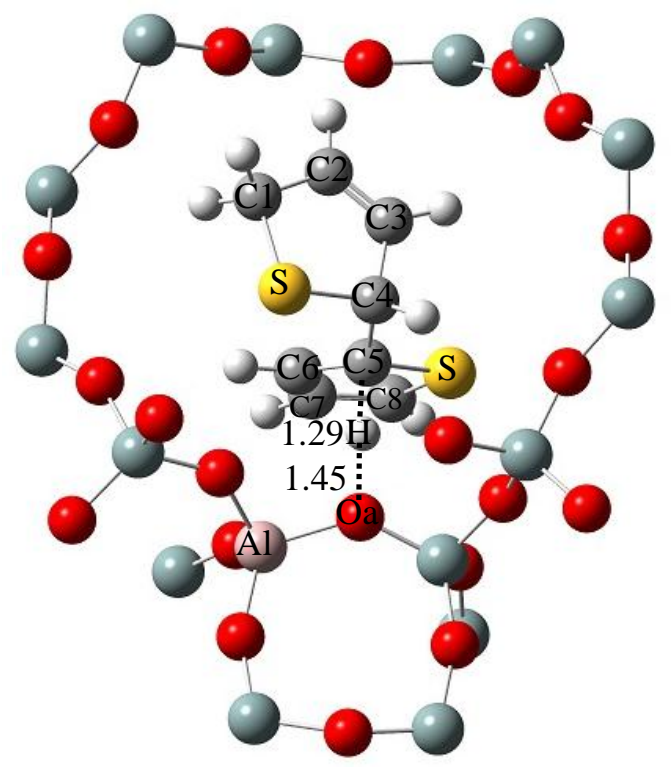

(a)

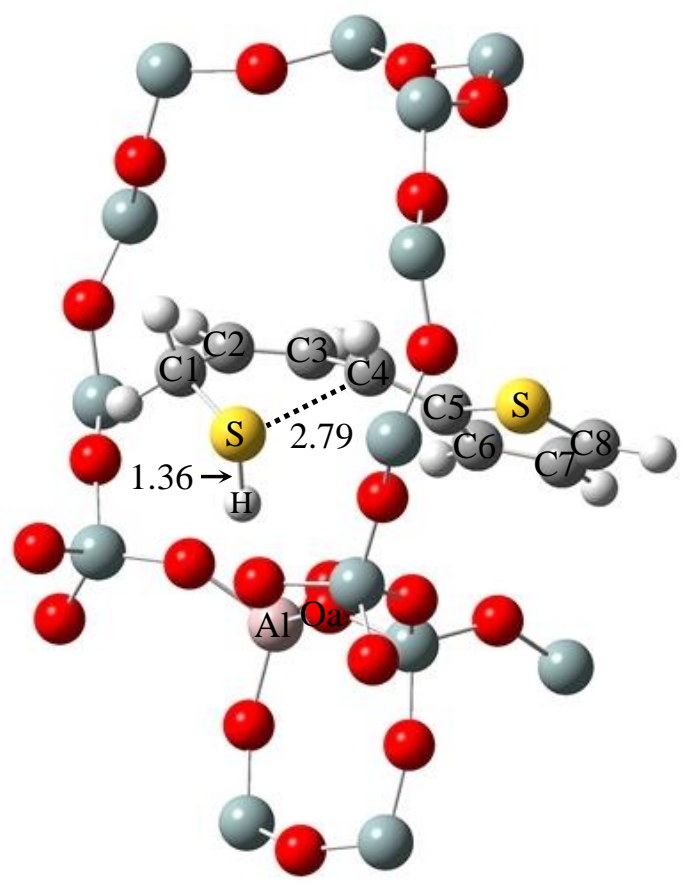

(c)

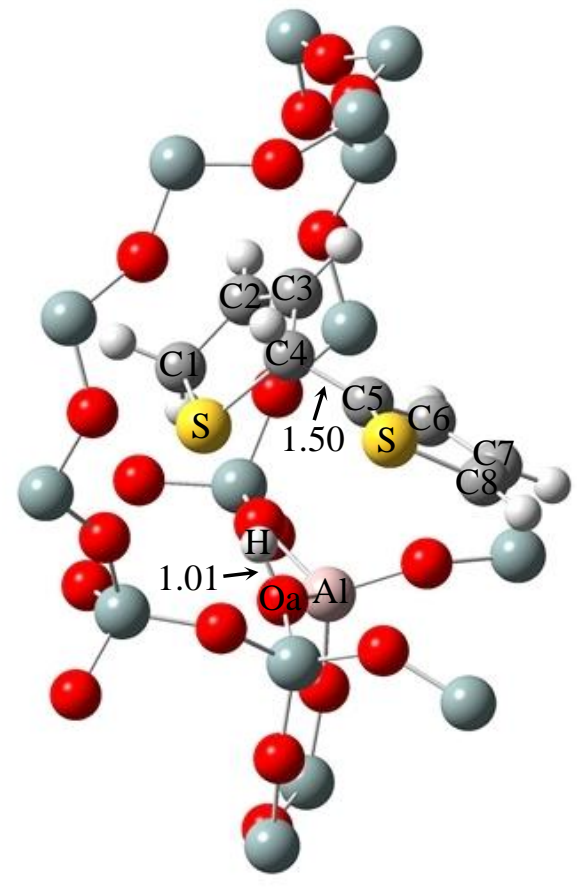

(b)

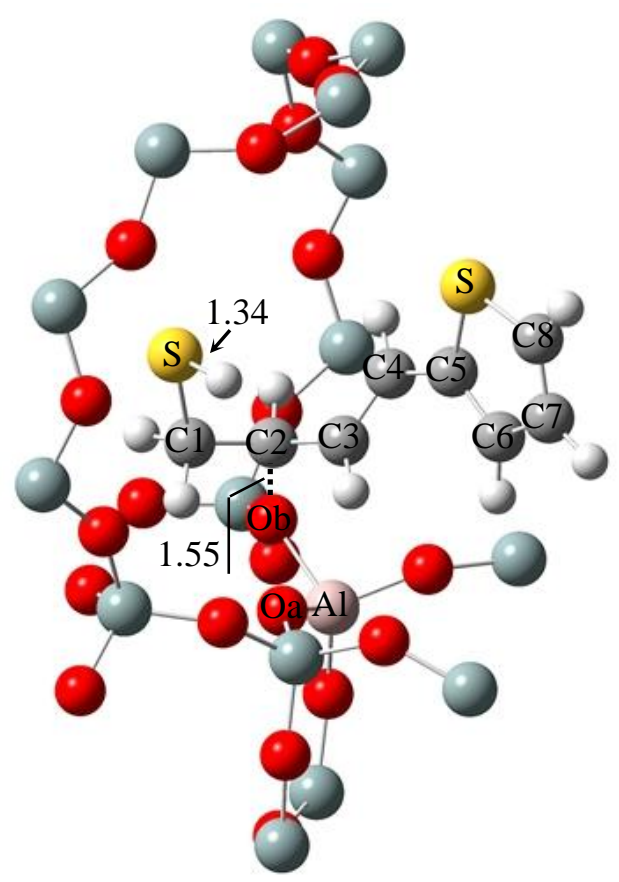

(d)

Figure 7. Optimized structures of (a) TS-TH-4, (b) complex-TH-3, (c) TS-TH-5, and (d) INT-TH-4. 


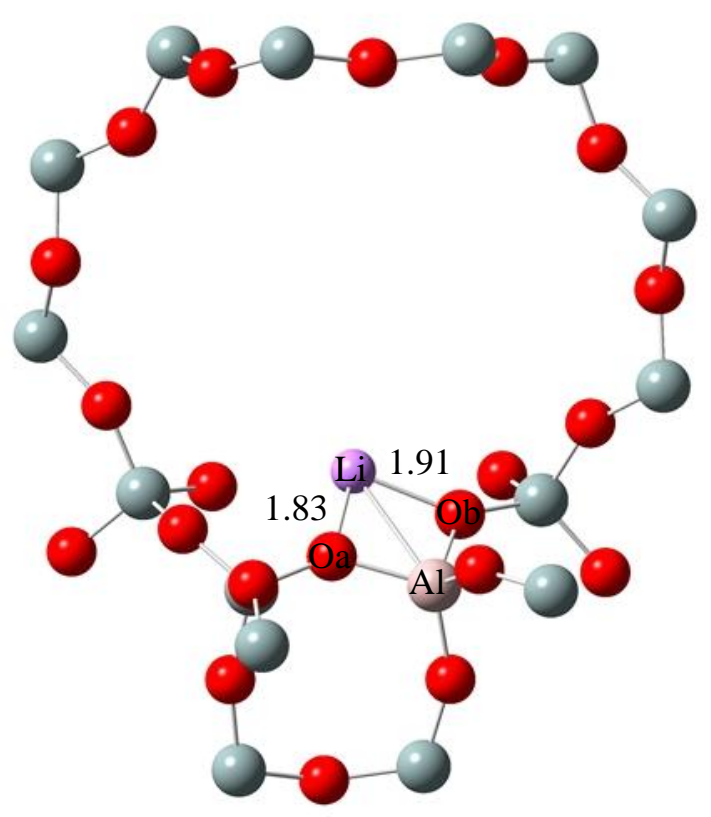

(a)

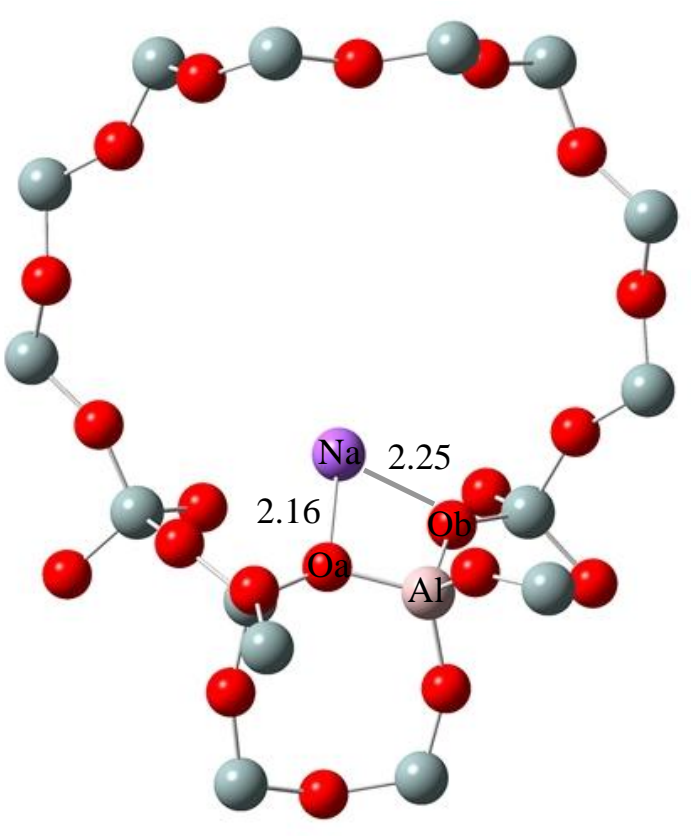

(b)

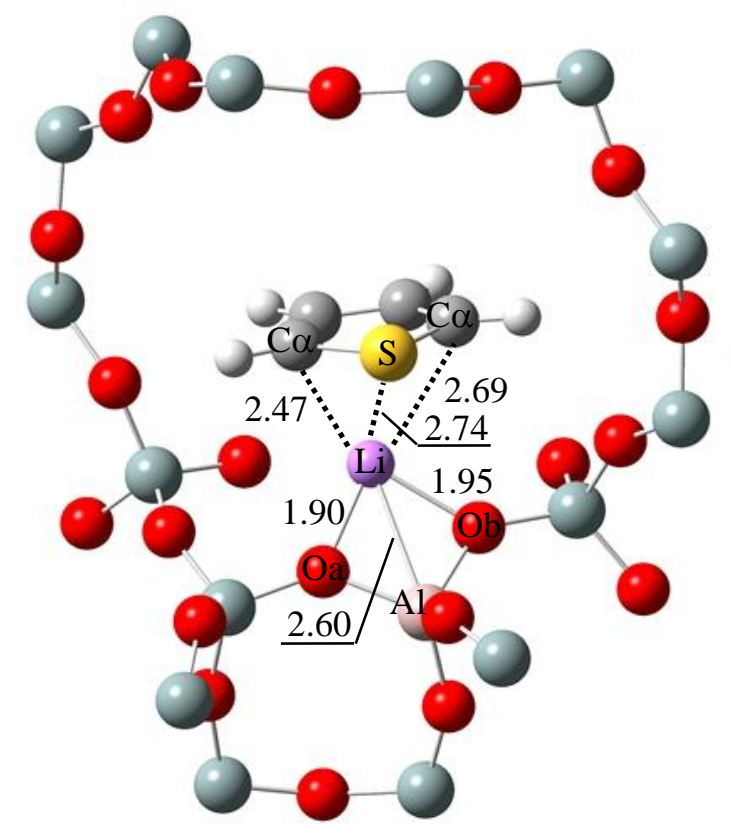

(c)

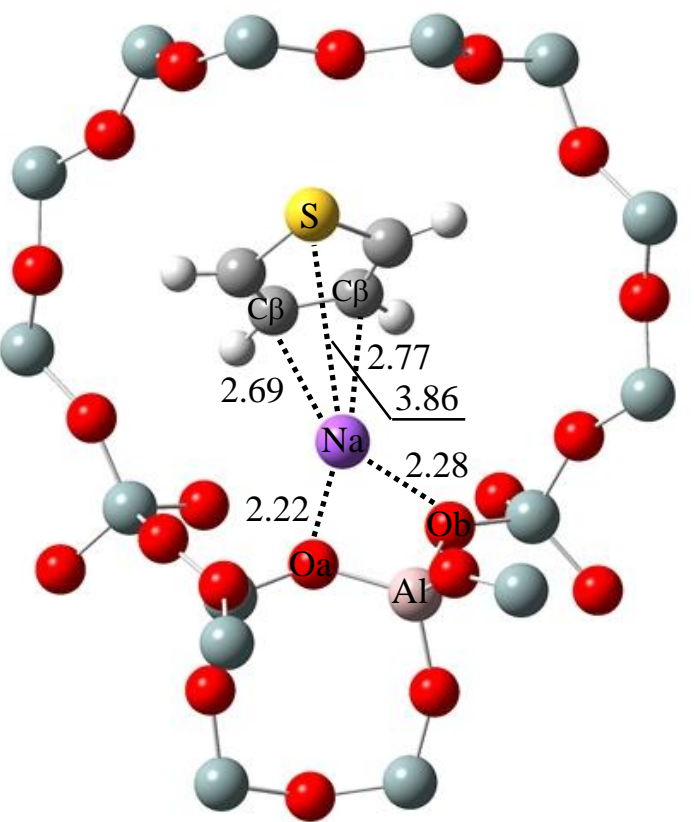

(d)

Figure 8. Optimized structures of (a) Li-beta zeolite, (b) Na-beta zeolite, (c) complex-Li-1 and (d) complex-Na-1. 


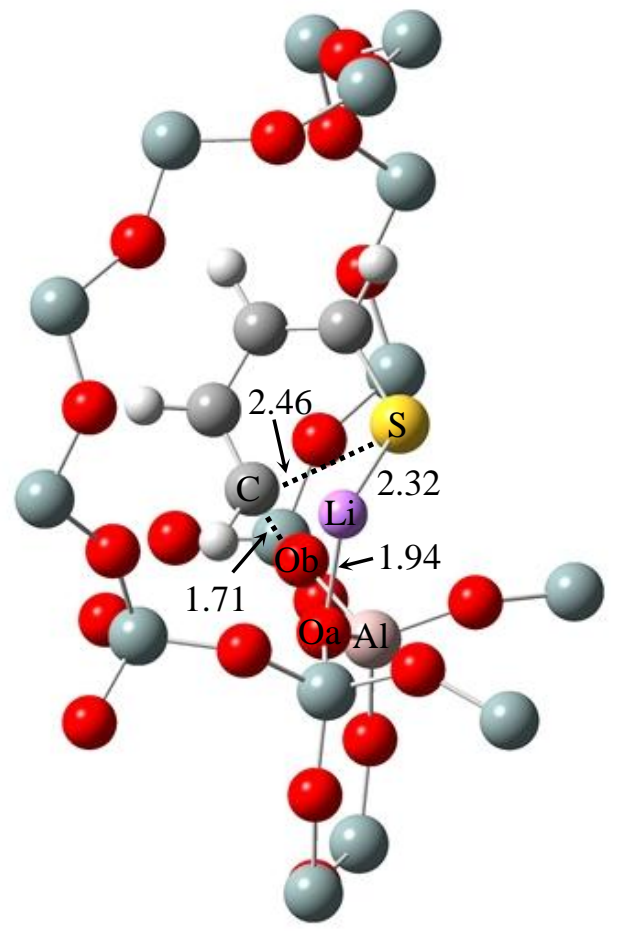

(a)

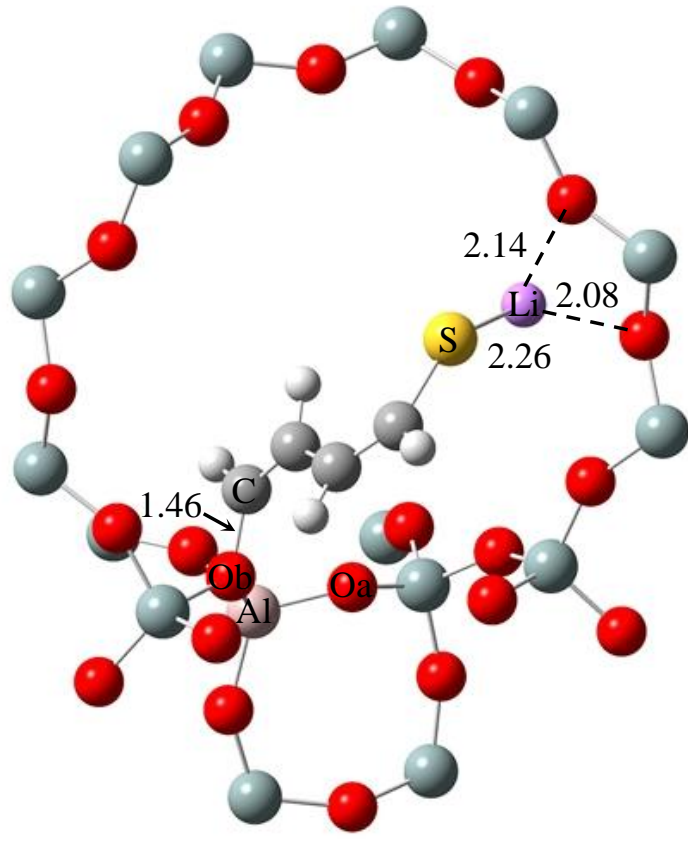

(b)

Figure 9. Optimized structures of (a) TS-Li-1, and (b) INT-Li-1. 


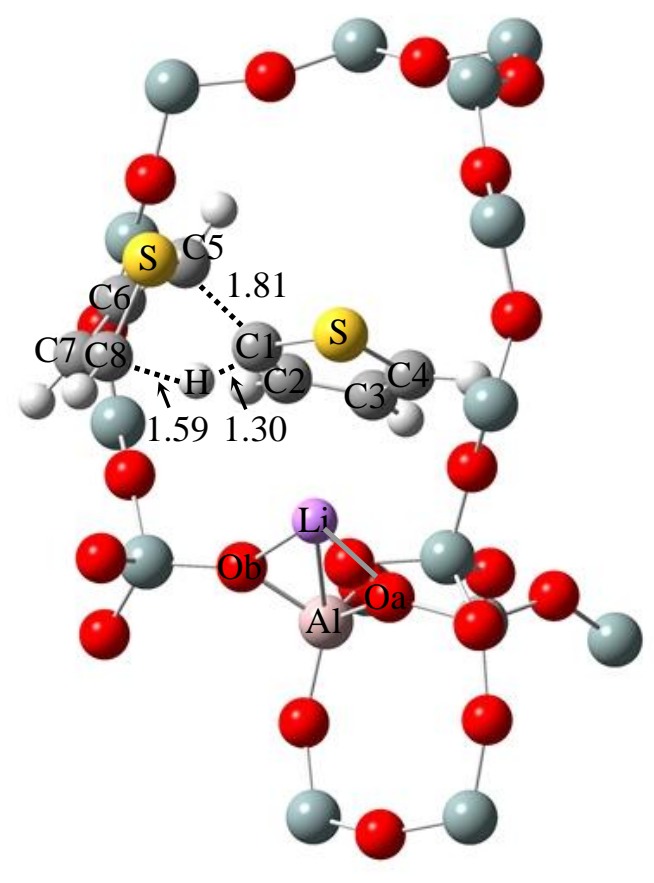

(a)

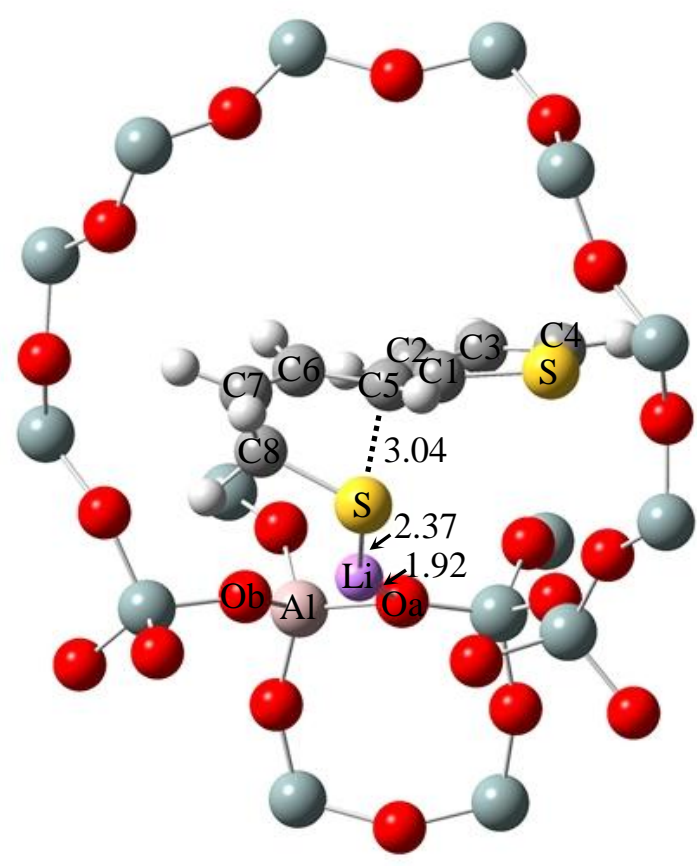

(c)

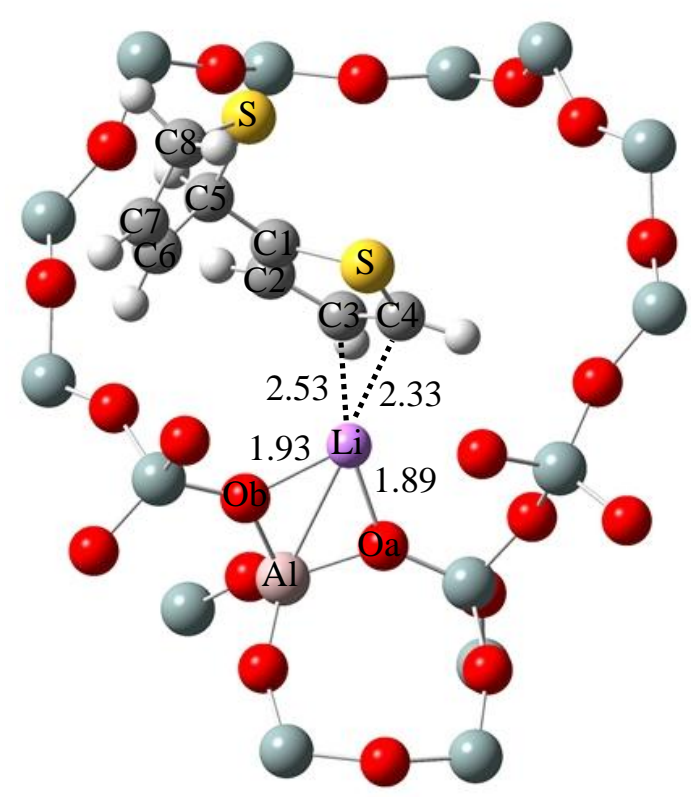

(b)



(d)

Figure 10. Optimized structures of (a) TS-Li-2, (b) complex-Li-3, (c) TS-Li-3, and (d) INT-Li-2. 
Table 1 Activation barriers (kJ/mol) for $\mathrm{C}-\mathrm{S}$ bonds cracking steps of TS-TH-1, TS-2CH3 and TS-BT, and energy decompositions in QM and MM contributions.

\begin{tabular}{cccc}
\hline Species & MM & QM & ONIOM \\
\hline TS-TH-1 & 15.25 & 411.64 & 426.90 \\
TS-2CH3 & 20.99 & 354.86 & 375.85 \\
TS-BT & 5.75 & 374.55 & 380.30 \\
\hline
\end{tabular}


Table 2 Activation barriers (kJ/mol) for the TS-TH-2, TS-TH-3, TS-TH-4, and TS-TH-5, and energy decompositions in QM and MM contributions.

\begin{tabular}{cccc}
\hline Species & MM & QM & ONIOM \\
\hline TS-TH-2 & -8.91 & 78.80 & 69.89 \\
TS-TH-3 & -2.78 & 91.43 & 88.66 \\
TS-TH-4 & 4.54 & 25.45 & 29.99 \\
TS-TH-5 & -22.63 & 161.98 & 139.35 \\
\hline
\end{tabular}


Table 3 Activation barriers (kJ/mol) for the TS-M-1, and energy decompositions in QM and MM contributions $\left(\mathrm{M}=\mathrm{Li}^{+}, \mathrm{Na}^{+}, \mathrm{K}^{+}, \mathrm{Cu}^{+}\right.$, and $\left.\mathrm{Ag}^{+}\right)$.

\begin{tabular}{cccc}
\hline TS-M-1 & MM & QM & ONIOM \\
\hline $\mathrm{Li}^{+}$ & 3.18 & 450.13 & 453.31 \\
$\mathrm{Na}^{+}$ & 7.29 & 416.87 & 424.16 \\
$\mathrm{~K}^{+}$ & 13.55 & 406.11 & 419.66 \\
$\mathrm{Cu}^{+}$ & 12.22 & 376.62 & 388.84 \\
$\mathrm{Ag}^{+}$ & 9.52 & 405.10 & 414.62 \\
\hline
\end{tabular}


Table 4 Activation barriers (kJ/mol) for the TS-M-2 and TS-M-3, and energy decompositions in $\mathrm{QM}$ and $\mathrm{MM}$ contribution $\left(\mathrm{M}=\mathrm{Li}^{+}, \mathrm{Na}^{+}, \mathrm{K}^{+}, \mathrm{Cu}^{+}\right.$, and $\left.\mathrm{Ag}^{+}\right)$.

\begin{tabular}{ccccc}
\hline Species & Cations & MM & QM & ONIOM \\
\hline \multirow{5}{*}{ TS-M-2 } & $\mathrm{Li}^{+}$ & 4.76 & 237.32 & 232.56 \\
& $\mathrm{Na}^{+}$ & 2.16 & 254.36 & 256.52 \\
& $\mathrm{~K}^{+}$ & -11.18 & 261.67 & 250.49 \\
& $\mathrm{Cu}^{+}$ & 1.38 & 224.87 & 226.24 \\
& $\mathrm{Ag}^{+}$ & 3.26 & 255.28 & 258.54 \\
\hline TS-M-3 & $\mathrm{Li}^{+}$ & 11.83 & 159.21 & 171.04 \\
& $\mathrm{Na}^{+}$ & -6.88 & 236.21 & 229.33 \\
& $\mathrm{~K}^{+}$ & 13.93 & 254.42 & 268.35 \\
& $\mathrm{Cu}^{+}$ & -10.04 & 146.12 & 136.08 \\
& $\mathrm{Ag}^{+}$ & 0.73 & 176.03 & 176.76 \\
\hline
\end{tabular}




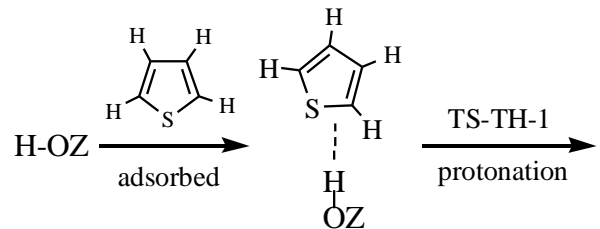

complex-TH-1

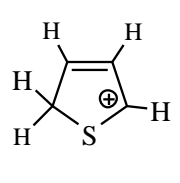



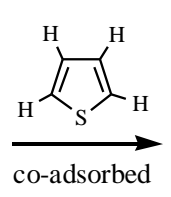

(C)

complex-TH-2

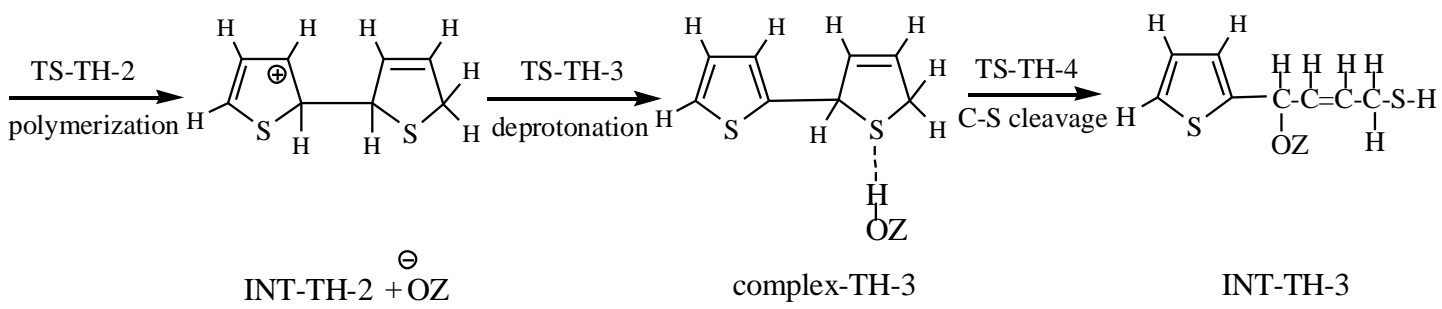

Graphics: Bimolecular C-S bond cracking mechanism of thiophene in H-beta zeolite. 